\title{
Self-criticisms toward a socially responsible science in the field of management
}

Business Research Quarterly

(C) The Author(s) 2021

Article reuse guidelines:

sagepub.com/journals-permissions DOI: 10.1 1 77/234094442। 1062230 journals.sagepub.com/home/brq

@SAGE

\author{
Jesús de Frutos-Belizón ${ }^{\mathrm{D}}$, Fernando Martín-Alcázar \\ and Gonzalo Sánchez-Gardey
}

\begin{abstract}
Management scholarship should be placed in a unique position to develop relevant scientific knowledge because business and management organizations are deeply involved in most global challenges. However, different critical voices have recently been raised in essays and editorials, and reports have questioned research in the management field, identifying multiple deficiencies that can limit the growth of a relatively young field. Based on an analysis of published criticisms of management research, we would like to shed light on the current state of management research and identify some limitations that should be considered and should guide the growth of this field of knowledge. This work offers guidance on the main problems of the discipline that should be addressed to encourage the transformation of management research to meet both scientific rigor and social relevance. The article ends with a discussion and a call to action for directing research toward the possibility and necessity of reinforcing "responsible research" in the management field.
\end{abstract}

\section{JEL CLASSIFICATION: M00, MIO}

\section{Keywords}

Management field, management research, Valley of Death, academic reward system, socially responsible science

\section{Introduction}

Research in the social sciences comprises a branch of human knowledge integrated by different fields of knowledge that define a long academic history. Some academic disciplines, such as economics, psychology, and sociology, have their origins in the late 18th and early 19th centuries. Conversely, the management discipline emerged from a practical need for skilled business managers at the end of the 19th century (Agarwal \& Hoetker, 2007), and since then this field has undergone significant growth (Birkinshaw et al., 2014; Honig et al., 2017). It seems clear that judging by the number of academics involved and the volume of research outputs provided, the field of management research has experienced impressive success. However, it is worth considering whether it is growing in the correct direction and whether it is providing substantial relevant knowledge to understand management processes.

Emerging criticisms in the literature question trust in research in the management field (Bedeian et al., 2010; Davis, 2015; Honig et al., 2017, 2018; Tsui, 2016). The knowledge generated by academics in the management field is often criticized because of its reduced relevance for practitioners (Bansal et al., 2012; Bartunek \& Rynes, 2014; Bullinger et al., 2015; Kieser \& Leiner, 2012). As Davis (2015) argues, it is necessary to reflect on why and for what scientific knowledge is generated in the management field. Management research should always aim to understand and explain the empirical puzzles in the business world and organizations. Therefore, the relevance to practice is central to management research. However, in many cases, management academics focus on issues that are irrelevant to professionals, and most research results are not normally documented in terms of applications, nor are

Department of Business Organization, University of Cádiz, Cádiz, Spain

\section{Corresponding author:}

Jesús de Frutos-Belizón, Department of Business Organization, University of Cádiz, II002 Cádiz, Spain.

Email: jesus.defrutos@uca.es 
they accessible to practitioners. Over the years, this problem has generated a sizable body of literature on bridging the relevance gap (Bansal et al., 2012; Bartunek \& Rynes, 2014; Bullinger et al., 2015; De Frutos-Belizón et al., 2019; Kieser \& Leiner, 2012). Nevertheless, after several decades of debate, and despite important efforts to bridge the research-practice gap, no solution seems to have been found, and the discussion continues in the literature. Likewise, according to the evidence shown in some papers, the management field has important deficiencies in its compliance with scientific standards of falsifiability, replicability, and data transparency, all of which are essential to generate scientific knowledge (Barley, 2016; Bedeian et al., 2010; Bettis et al., 2016; Goldfarb \& King, 2016; Honig et al., 2017; Lewin et al., 2016; Starbuck, 2016; Tsui, 2016). Recently, different critical voices through essays, editorials, and position papers have questioned research in the management field, criticizing the research as pursuing novelty over truth, lacking a connection with management practice, using poor methodological research practices, and exposing the vulnerability of its scientific claims (Barley, 2016; Bettis, Ethiraj, et al., 2016; Davis, 2015; Honig et al., 2018; Lewin et al., 2016; Starbuck, 2016; Tsui, 2016).

However, the relevance of management research goes beyond just the managerial profession, as it also has social implications. In fact, it could be considered that management scholars have a great opportunity with their research to guide business actions toward practices closer to a prosperous and sustainable socioeconomic context. As suggested by Barley (2010), from a reflective position, the academics that are a part of the management field should adopt a more pragmatic vision and reflect on how organizations and their management are transforming our society. Current societies rely on organizations as the primary social actors. Profit-making organizations are the most influential of all of them, surpassing governments in many cases. In different stages of history, and in certain contexts, other organizations, such as the church, have played this dominant role, but Western economies can currently be described as firm-driven systems. This development has exponentially increased the social relevance of management research and the social responsibility of academics in this field. Conscious of this, even some of the pioneers in the management field came to consider the discipline as a science-based professional activity that has the opportunity to contribute to the "greater good" (Drucker, 1974; Simon, 1967; Taylor, 1914). However, it is surprising that this social commitment of the discipline has been traditionally overlooked. J. P. Walsh et al. (2003) analyzed 1,738 works published from 1958 to 2000 in the Academy of Management Journal. They concluded that, "scholarship in our field has pursued society's economic objectives much more than it has its social ones" (J. P. Walsh et al., 2003 , p. 859). The authors verified that over $70 \%$ of the articles focused on performance-oriented outcomes while the rest only had a social orientation in their results. Tsui and Jia (2013) replicated the previous study but focused on papers drawing on Chinese samples in the period from 1981 to 2012. Their findings showed that despite China having a more socialist doctrine, economically it has an ultra-capitalist system that does not equally consider the social and economic content of firms' outcomes. The findings showed that over $80 \%$ of the works in English journals and over $90 \%$ in Chinese journals were clearly oriented on performance or economic outcomes.

As a response to these problems, a new vision has recently emerged that considers the necessity of transforming the research developed in the field of management toward a more responsible science (Community for Responsible Research in Business and Management [CRRBM], 2017, revised 2020; Tsui, 2013, 2016). This trend assumes that the central problems suffered by the management field are connected, given that the relevance of the research is debatable when the quality is in doubt. To inspire changes, the $\mathrm{CRRBM}^{1}$ (2017, CRRBM (2017)) proposes a set of principles that guide research in the field of management to build a solid body of knowledge (epistemic values) with social implications (social values). As research is fundamentally evaluated by its publication in top journals, the social implications of the knowledge generated are frequently underestimated. Currently, scientific publication is rewarded over other research outputs in academic careers. Since research quality judgments are difficult, systems increasingly rely on "impact" measures that can be easily evaluated. As a result, the current system of rewards in the academe has meant that for most researchers obtaining a publication in a top journal has high priority for the development of their academic career, propagating the so-called publishor-perish culture (Barley, 2016; Lewin et al., 2016; Starbuck, 2016).

Therefore, in view of the relevance and reliability problems suffered by this field of knowledge, the current article invites discussion and debate on the need to substantively rethink management research toward a responsible science perspective. However, we find in the literature various criticisms from opinion statements and without apparent connection. Therefore, since the published criticisms do not represent a structured field, we review the literature to provide a complete background of the main concerns about management research that could hinder the development of a responsible science. This work makes important contributions. On one hand (a) based on an analysis of published criticisms of management research, we try to shed further light on previous discussions about the state of management research by identifying shortcomings that challenge the growth of a relatively young field. This represents a relevant contribution that differentiates this work from previous studies, since, according to our knowledge, this article 
offers guidance about the main problems of the discipline that should be addressed to encourage the transformation of management research to meet both scientific rigor and social relevance. On the other hand, as a (b) second contribution, from the ideals of socially responsible science, we encourage the transformation of the management research field by considering both epistemic and social values, recognizing the mutual dependency between science and society and fulfilling the criteria of rigor and relevance.

To do this, the structure of the article is as follows. Initially, we develop a background section summarizing the main problems already raised by past syntheses. Next, we explain the methodology used to review the literature: criteria for the selection of articles, coding, and content analysis. Specifically, after this rigorous selection process, 70 papers were considered as primary sources in our data sample. In the following section, we describe the main flaws on which to act in the management field and propose guidance on the possible solutions that should be implemented. Finally, the article concludes with a discussion and call to action for directing research toward the possibility and necessity of reinforcing "responsible research" in the management field.

\section{The crisis of the management field}

The management discipline emerged from a practical need for skilled business managers at the end of the 19th century (Agarwal \& Hoetker, 2007), and since then, this field has undergone significant growth (Birkinshaw et al., 2014; Honig et al., 2017). In the years after the Second World War, mainly in the United States, we witnessed a substantial increase in the number and quality of business schools that contributed to the rigor of the discipline through their academic programs. However, the outpouring of the systematic and empirical research that has supported the management discipline is frequently considered to have emerged in the mid-1950s (Agarwal \& Hoetker, 2007). It is considered that the management field reached the necessary legitimacy as a scientific discipline when business schools adopted the natural sciences model in response to the challenges raised in two seminal reports published in 1959 (Gordon \& Howell, 1959; Lewin et al., 2016; Pierson, 1959). The first of them, published by the Ford Foundation and written by Robert Aaron Gordon and James Edwin Howell (1959), was titled "Higher Education for Business." The second, issued by the Carnegie Foundation and written by Frank C. Pierson, was titled "The Education of American Businessmen: A Study of University-College Programs in Business Administration" (Pierson, 1959). Both reports criticized business schools for the impracticality of their outputs and their lack of scientific content. Specifically, Gordon and Howell (1959) assessed management research, expressing that, "the business literature is not, in general, characterized by challenging hypotheses, well-developed conceptual frameworks, the use of sophisticated research techniques, penetrating analysis, the use of evidence drawn from relevant underlying disciplines [. . .], or significant conclusions" $(1959$, p. 379). At that time, the state of business school education was largely characterized by a trade school orientation, without deep scholarly content. Both reports criticized the lack of scientific foundations of business schools and called for increasing attention to scientific rigor and propelling business research into the realm of social sciences (Gordon \& Howell, 1959; Pierson, 1959). These critical reports generated a "scientification" in the management field, and scholars developed a more rigorous research based on sophisticated empirical analyses. This scientification process assumed that the management research must adopt the positivist model of the natural sciences. These two reports encouraged business schools to give faculty more time for research tasks and to approach other academic disciplines that contribute to the growth of the discipline (Porter \& McKibbin, 1988). According to the arguments of these reports, the establishment of links with nearby disciplines would suppose a way to obtain a greater legitimacy and a significant base resource, given the limited stock of knowledge and research of management science in the early years (Gordon \& Howell, 1959; Pierson, 1959). Therefore, since the management field lacked relevant maturity as a discipline, it seems logical that its growth and evolutionary path is significantly influenced by ideas from other fields of knowledge such as economics, sociology, psychology, anthropology, and mathematics (Birkinshaw et al., 2014). As noted by Porter and McKibbin (1988), over the 25 years following the referred reports, the "research agenda for most schools looked rather different than it had in the 1950s, both in amount and character" (Porter \& McKibbin, 1988, p. 166). Since the 1960s, the discipline has had considerable evolutionary growth, as the number of publications and articles published in management increased in a remarkable way (Honig et al., 2017; Porter \& McKibbin, 1988; Van Baalen \& Karsten, 2012). However, it is worth considering whether it is growing in the correct direction and whether it is providing substantive relevant knowledge to understand management processes.

Recently, different critical works have questioned research in the management field, criticizing the fact that research is pursuing novelty over truth, as well as its lack of connection with management practice, the poor methodological research practices, and the vulnerability of its scientific claims (Barley, 2016; Bettis et al., 2016; Davis, 2015; Honig et al., 2017, 2018; Lewin et al., 2016; Starbuck, 2016; Tsui, 2016). Currently, academic careers reward publication over other research outputs. Since research quality judgments are difficult, systems rely on "impact" measures that can be easily evaluated. Therefore, just as in many other academic disciplines, it also happens that management research is driven by the standards established by journals and academic reward systems. As a result, academics seek novelty and impact 
in their research outputs to obtain publications more easily and advance their academic careers (Davis, 2015). As some works have supported, this is intensified and reinforced by the way in which $\mathrm{PhD}$ students are trained, the criteria for selecting manuscripts of journal reviewers and editors, and the rewards policies that award positions and promotions (Barley, 2016; Lewin et al., 2016; Starbuck, 2016). As stated by Honig et al. (2018), through a dialogue with editors, the current system of rewards in the academy has meant that for most of the researchers, obtaining a publication in a top journal has high priority for the development of their academic career, implementing the so-called publish-or-perish culture. Similarly, a few years earlier, Birkinshaw et al. (2014) in an open discussion on the state of the management field and its future perspectives showed their concern about the distancing from practice and the generation of "fetishist" theory, regardless of its instrumental value for the professional world and society. Likewise, as Davis (2015) argues, it is necessary to reflect on why and for what scientific knowledge is generated in the management field. Management research should always aim to understand and explain the empirical puzzles in the business world and organizations. Therefore, the relevance to practice is central to management research (Bansal et al., 2012; Bartunek \& Rynes, 2014). However, in many cases, management academics focus on issues that are irrelevant to professionals, and most research results are not normally documented in terms of applications, nor are they accessible to practitioners (Bansal et al., 2012; Bullinger et al., 2015; Kelemen \& Bansal, 2002). In fact, a relevant number of works in the literature on bridging the relevance gap in the management field has accumulated over the years, and this gap is an ongoing concern for many management scholars (Bansal et al., 2012; Bartunek \& Rynes, 2014; Bullinger et al., 2015; Cohen, 2007; Kieser \& Leiner, 2012). As some more reflective works have proposed, this problem has its origin in the adoption in the past of a positivist paradigm closer to the natural sciences that caused the search for rigor over relevance (De Frutos-Belizón et al., 2019; Lewin et al., 2016; I. Walsh et al., 2015). Therefore, according to these works, a more pragmatic and interpretive reconsideration of the paradigm from which management science is focused is necessary (De Frutos-Belizón et al., 2019). For example, the focus should be on other more interpretive research paradigms such as grounded theory (I. Walsh et al., 2015).

However, paradoxically this empiricist and positivist emphasis to obtain legitimacy as a discipline in the past has not guaranteed that there are not multiple criticisms of bad methodological practices in the management field (Bettis, Ethiraj, et al., 2016; Sartal et al., 2021). According to the evidence that some papers show, the management field has important deficiencies in the compliance of scientific standards of falsifiability, replicability, and data transparency, which are essential to generate scientific knowledge (Barley, 2016; Bedeian et al., 2010; Bettis, Ethiraj, et al., 2016; Goldfarb \& King, 2016; Honig et al., 2017; Lewin et al., 2016; Sartal et al., 2021; Starbuck, 2016; Tsui, 2016). All this happens no more than six decades after the publication of the Ford Foundation and Carnegie Commission reports. For example, Bedeian et al. (2010) surveyed management professors, asking them about their perceptions relative to research in the discipline. The empirical evidence extracted confirmed that they harbor skepticism about the reliability of published research. With a similar objective, Goldfarb and King (2016) assessed a sample of 300 published studies in top outlets for research on management. They estimated that $24 \%-40 \%$ of the reported results would probably not be confirmed if the study were repeated. Various works have shown their concern regarding various methodological problems, promoting debates and providing recommendations to editors and journals to change this situation. However, the previous literature is still varied and focuses on issues of a different nature. For example, some studies that have warned of misinterpretations of $p$-values, the statement of hypotheses after knowing the results, or the specific selection of variables in a model (Aguinis et al., 2017; Bedeian et al., 2010; Bettis, Ethiraj, et al., 2016; Orlitzky, 2012; Starbuck, 2016). Others, such as Aguinis et al. (2013), criticized the erroneous methodological treatment of outliers in management research. Cho and Kim (2015) refuted some of the erroneous properties attributable to the alpha coefficient, criticizing its misinterpretation and its extensive use as an indicator of absolute reliability in the management field. By contrast, other works, such as Roloff and Zyphur (2019) or Sartal et al. (2021), consider that replicability problems also come in many cases from the lack of information provided on the methodology used, blaming the lack of transparency as one of the fundamental problems. In short, as Aguinis et al. (2017) argue, a manuscript is more likely to be considered for publication if it contains significant results or the hypotheses are supported.

Recently, based on these criticisms, the Community for Responsible Research for Business and Management (CRRBM) published a relevant position paper that inspires, encourages, and supports credible and useful research in the business and management disciplines. This document advocates development and proposes seven principles that support the development of responsible research. Clearly, these principles seem capable of guiding a substantive rethinking of our field of knowledge toward a responsible science that generates useful knowledge for the business world and society. However, compliance with these principles can be threatened by various problems that dominate the management field.

Davis (2015) made an interesting critical metaphor comparing the architecture of research in the field of management with the famous Winchester Mystery House (San José, California). The legend states that the widow of the 
founder of the Winchester rifle company would be pursued by the ghosts of those people who died by her husband's rifles unless he built a mansion to house these spirits. Therefore, Winchester Mystery House would not own a master building plan, but its construction would be its sole purpose. Davis (2015) wonders whether after several decades of building the management knowledge field, the discipline is facing an expensive ornamental building with no practical purpose, like the Winchester Mystery House. According to the latest records of 2019 published by the Web of Science, over 9,000 works are published every year in more than 226 journals in the management field, and the number increases every year. However, we should ask ourselves whether we are clear about where we are going in our construction. Therefore, it is necessary to identify the potential burdens that can seem to be more, such as a mysterious house with any construction being an end.

As we have seen in the literature, critical evidence has led to identifying various deficiencies suffered by research in the management field. However, these criticisms represent an unstructured field, with multiple criticisms without apparent connection and from various reflections or position papers. Therefore, in the following section, we review the literature to provide a complete background of the main concerns about management research that could hinder the growth of this field of knowledge.

\section{Method}

As we have indicated, the objective of the literature review was to identify in the published criticisms of management research the main concerns about management research that could hinder the development of a responsible science. Specifically, with the development of this systematic review, we propose a conceptual consolidation in a fragmented sphere of multiple criticisms of research in the management field. Systematic reviews add rigor to the review process and its results by following transparent and reproducible procedures (Sartal et al., 2021; Tranfield et al., 2003). In our review, following Tranfield et al. (2003), we have used systematic data search and analysis procedures, specifically, through three stages: data collection, data coding, and data analysis.

\section{Step I: data collection}

At this stage, we plan the literature review and define the scope and range of the literature under analysis (Tranfield et al., 2003). To identify the relevant publications for our study, the searches were developed using the international electronic databases, "ISI Web of Science (WoS; Thomson Reuters)" and "ABI / INFORM Complete." These databases contribute to our study what some authors call "certified knowledge" (Ramos-Rodríguez \& Ruíz-Navarro, 2004) for the impact of the analyzed research. These data sources are reliable and common in many bibliometric studies carried out in the management field (Thunnissen \& GallardoGallardo, 2019), since they contain sufficiently broad information for any type of study. The objective of the search in these databases was to identify peer-reviewed published criticisms of management research in multiple formats such as regular papers, position papers, editorials, or opinion statements.

Five criteria guided our article selection process. Specifically (a) we restricted the time frame of our search to 2009-2020, inclusive. To ensure a review of the most recent relevant concerns published in our field, we restricted sources to those published in the past decade (beginning from 2009), as we considered this as an appropriate period to analyze the criticisms that remain latent in the current field of knowledge. In addition, most relevant work that criticizes the research in the field of management only emerged in this decade, a period of boom in works that reflect on the development of research and its limitations. However, as will be shown below, the reference lists of all articles initially included in the review were examined using the snowball method, which permitted us to include additional relevant papers in our review. However (b) those categories of publications that were not peer-reviewed, without available authorship, or with content unrelated to research in the field of management were excluded. Furthermore (c) we excluded conference articles, books, book chapters, theses, and monographs. To ensure the scientific quality of our primary sources in our data sample (d) we selected papers from journals indexed in the Journal Citation Reports (JCR) and SCOPUS database with at least Q2 in the SCImago Journal Rank (SJR). Finally (e) as international academic debate depends predominantly on English papers, only papers published in English were considered.

During the search process ${ }^{2}$, search terms included keyword combinations with Boolean operators ("and," "or"), for example, "research - practice gap," "publication practices 'replication," "management research/field 'rigor-relevance gap,"” "science-practice gap, and 'ethical problems."” The different search string combinations resulted in 169 valid results in WoS and 223 valid results in "ABI / INFORM Complete." However, we found a significant overlap between the results of both databases, and the duplicates were eliminated. After this first filter, 123 preliminary results were considered relevant for our review.

Following the selection process, we obtained the fulltext articles through their databases or other open-access channels (ResearchGate or Google Scholar). We performed a second manual filtering of the results to qualitatively determine which publications identified in the search met the criteria and could therefore be included in the literature review. To mitigate any potential bias, the evaluation was based on the independent judgment of 
two members of the research team, who reviewed the titles and abstracts or read the full texts when necessary. After this second manual refinement, some preliminary documents were also excluded, with additional reasons for this. For example, some papers that were initially classified as scientific publications were verified to be conference papers or publications in non-indexed journals. Some editorial papers were also excluded since, although they initially met the inclusion criteria, they were introductions to a special issue and did not focus on any specific topic in-depth. Likewise, some full texts were unobtainable and were therefore excluded. Finally, after this selection process, 70 papers comprised the primary sources for our data sample (Table 1). As two of the authors were involved in this process, we computed a Cohen's Kappa indicator on the agreement in their decisions. The Cohen's Kappa index is an index of interrater agreement between two raters. Unlike a simple percentage of agreement, Cohen's Kappa index adjusts the effect of chance on the percentage of agreement obtained (Cohen, 1960), and is therefore considered as a robust measure. Normally, a value higher than .40 suggests satisfactory interrater agreement (Fleiss, 1981); in this first step, a value greater than .80 was found for all articles evaluated by the two authors. Likewise, Cohen's Kappa values were also statistically significant at an alpha level of .001 or .01 .

This final sample of 70 articles was organized in an Excel spreadsheet in which descriptive information was included for each article (author, year of publication, title, journal, number, volume, keywords, and abstract) (Appendix 1). These descriptive data were reviewed to avoid any errors in their writing and to ensure the accuracy and consistency of the information.

\section{Step 2: information coding}

The coding stage allows you to classify and divide large amounts of accumulated data into lower and coherent parts to later analyze how they are related. Once a set of articles is selected as primary sources, we develop a coding scheme and analysis method according to the objective of our study (Potter \& Levine-Donnerstein, 1999; Sartal et al., 2021; Zupic \& Čater, 2015). As we have previously noted, the objective of the literature review is to identify, in a particularly fragmented field, the main concerns about management research that could hinder the development of a responsible science. Therefore, in accordance with the objective of our study, we reviewed the content of the articles that were a part of our data sample. Specifically, we performed a content analysis of the title and keywords provided by the authors, the abstracts, and even the full texts. This analysis made it possible to discover links between subject areas, trace their development, and establish a codified structuring of emerging works in the literature on limitations in management research. The content analysis was developed through exhaustive parallel coding procedures independent of two of the members of the research team, which allowed us to verify the reliability of the analysis. Specifically, we created coding categories and subcategories to structure the literature around information related to the analyzed limitations, methodological concerns, more general criticisms, and proposals for improvement on research in the management field, for example.

The coding process involved three stages. In the first stage, we randomly selected a few articles for two authors to propose independent coding and then to compare and discuss the proposed categories and subcategories. This step helped determine specific rules and definitions for possible coding categories that helped to provide uniformity to this procedure. In the second stage, we randomly divided the rest of the manuscripts among two members of the scientific team, so that each one could code the assigned articles according to the established coding guidelines and the list of codes. Finally, in the third stage, we discussed the shared codings and disagreements that arose in specific categories. This detailed and rigorous process enabled us to reduce possible bias in the qualitative interpretation of each manuscript. This was verified by confirming that the agreement between the coders in the research team was at a satisfactory range of Cohen's Kappa values. For example, in the second step, there were two authors involved in the encoding process, and in the 70 articles evaluated, we obtained Cohen's Kappa values greater than .50 and that were statistically significant at an alpha level of either .001 or .01 . Furthermore, values greater than .80 were obtained for most articles. Thus, these values indicate very good interrater agreement in the encoding process. Only five articles had moderate Cohen's Kappa values between .50 and .80. However, the disagreements were easily discussed and resolved by the coders.

\section{Step 3: analysis and dissemination of information}

Once the content of the manuscripts was coded, the main findings of the literature review were analyzed (Tranfield et al., 2003). Specifically, the analysis of the content data collected was carried out in another Excel file. From the information ordered according to the coding template, all the information of each article was gathered, both descriptive and on specific codified content. In the second Excel analysis sheet, we used tables to structure the information obtained in terms of the frequency of each category, the subcategory of coded content, and the qualitative interpretation of the full text. The final analysis of these tables by the scientific team allowed us to recognize and identify 
Table I. Publications included in this review.

\begin{tabular}{|c|c|c|c|}
\hline Journal & No. of articles & $\%$ & Articles \\
\hline Organizational Research Methods & 11 & $15.49 \%$ & $\begin{array}{l}\text { Aguinis et al. (202I); Cho and Kim (20I5); Cortina and Landis } \\
\text { (20II); Gibbert et al. (202I); Gioia et al. (20I3); Jebb and Woo } \\
\text { (20I5); Jonsen et al. (20I8); Kruschke et al. (20I2); O'Kane } \\
\text { et al. (202I); Orlitzky (20I2); I. Walsh et al. (20I5) }\end{array}$ \\
\hline Journal of Management Studies & 5 & $7.04 \%$ & $\begin{array}{l}\text { Bluhm et al. (20I I); Cornelissen (20I7); Kieser and Leiner } \\
\text { (2009); Starkey et al. (2009); Üsdiken (2014) }\end{array}$ \\
\hline $\begin{array}{l}\text { Academy of Management Learning } \\
\text { \& Education }\end{array}$ & 4 & $5.63 \%$ & $\begin{array}{l}\text { Bedeian et al. (20I0); Bergh et al. (2017); Honig et al. (20I7); } \\
\text { Pettigrew and Starkey (20I6) }\end{array}$ \\
\hline Strategic Management Journal & 4 & $5.63 \%$ & $\begin{array}{l}\text { Aguinis \& Solarino (20I9); Bettis (20I2); Bettis et al. (20I6); } \\
\text { Ethiraj et al. (20|6) }\end{array}$ \\
\hline Journal of Management Inquiry & 4 & $5.63 \%$ & $\begin{array}{l}\text { Baum (20I2); De Man et al. (2020); Kieser and Leiner (20I2); } \\
\text { Shani and Coghlan (20I4) }\end{array}$ \\
\hline Journal of Management & 4 & $5.63 \%$ & $\begin{array}{l}\text { Andraszewicz et al. (20I5); Bartunek and Rynes (20I4); } \\
\text { Hollenbeck and Wright (20I7); McKee and Miller (20I5) }\end{array}$ \\
\hline $\begin{array}{l}\text { Management and Organization } \\
\text { Review }\end{array}$ & 4 & $5.63 \%$ & $\begin{array}{l}\text { Leung (20II); Lewin et al. (20I6); Tsui (20I3); Tsui and Jia } \\
(2013)\end{array}$ \\
\hline Administrative Science Quarterly & 3 & $4.22 \%$ & Barley (20I6); Davis (20I5); Starbuck (20I6) \\
\hline Academy of Management Journal & 3 & $4.22 \%$ & Bansal and Corley (20II); George (20I4); Pratt (2009) \\
\hline Academy of Management Annals & 2 & $2.81 \%$ & Aguinis et al. (20I8); Kieser et al. (20I5) \\
\hline $\begin{array}{l}\text { Academy of Management } \\
\text { Perspectives }\end{array}$ & 2 & $2.81 \%$ & Bansal et al. (20I2); Honig et al. (20I8) \\
\hline BRQ Business Research Quarterly & 2 & $2.81 \%$ & $\begin{array}{l}\text { Molina-Azorín et al. (2020); Thunnissen \& Gallardo-Gallardo } \\
\text { (2019) }\end{array}$ \\
\hline European Management Journal & 2 & $2.81 \%$ & Cassell (2016); Runfola et al. (20I7) \\
\hline Journal of Business Ethics & 2 & $2.81 \%$ & McLeod et al. (20I8); Roloff and Zyphur (20I9) \\
\hline $\begin{array}{l}\text { Journal of International Business } \\
\text { Studies }\end{array}$ & 2 & $2.81 \%$ & Aguinis et al. $(2017,2020)$ \\
\hline $\begin{array}{l}\text { Aslib Journal of Information } \\
\text { Management }\end{array}$ & I & $1.40 \%$ & Hangel and Schmidt-Pfister (20I7) \\
\hline Academy of Management Review & 1 & $1.40 \%$ & Corley and Gioia (201I) \\
\hline The Leadership Quarterly & I & $1.40 \%$ & Antonakis (2017) \\
\hline $\begin{array}{l}\text { Scandinavian Journal of } \\
\text { Management }\end{array}$ & 1 & $1.40 \%$ & Bullinger et al. (2015) \\
\hline Public Administration Review & I & $1.40 \%$ & Vogel and Homberg (202I) \\
\hline Personnel Psychology & 1 & $1.40 \%$ & Bosco et al. (2016) \\
\hline Research Policy & 1 & $1.40 \%$ & Osterloh and Frey (2020) \\
\hline Organization Science & I & $1.40 \%$ & Schwab et al. (20II) \\
\hline Organization & I & $1.40 \%$ & Macdonald and Kam (20II) \\
\hline Management Science & I & $1.40 \%$ & McShane and Gal (20I5) \\
\hline Management Research Review & I & $1.40 \%$ & De Frutos-Belizón et al. (2019) \\
\hline Journal of Organizational Behaviour & I & $1.40 \%$ & Mathieu (2016) \\
\hline Journal of Business and Psychology & I & $1.40 \%$ & Murphy and Aguinis (2019) \\
\hline $\begin{array}{l}\text { International Journal of } \\
\text { Management Reviews }\end{array}$ & 1 & $1.40 \%$ & Symon et al. (20/8) \\
\hline $\begin{array}{l}\text { Human Resource Management } \\
\text { Journal }\end{array}$ & 1 & $1.40 \%$ & Harley (20I5) \\
\hline $\begin{array}{l}\text { Cross Cultural \& Strategic } \\
\text { Management }\end{array}$ & 1 & $1.40 \%$ & Tsui (2016) \\
\hline
\end{tabular}

the types of criticism raised in the recent literature about research in the management field. Specifically, we grouped the different problems identified in the literature and coded them around five core concerns (Table 2). Thus, for example, within one of these core issues called scientific apophenia, we grouped other related categories and subcategories of problems previously identified as the handling of outliers or the incorrect use of control variables (Table 3). These five critical areas will be addressed in the following section. 
Table 2. Articles and core problems extracted from the literature review.

\begin{tabular}{|c|c|c|c|c|c|}
\hline Articles & $\begin{array}{l}\text { Scientific } \\
\text { apophenia }\end{array}$ & $\begin{array}{l}\text { Incorrect use of } \\
\text { significance tests/ } \\
\text { interpretation of } p \text {-value }\end{array}$ & $\begin{array}{l}\text { Discrimination } \\
\text { of qualitative } \\
\text { methodology }\end{array}$ & $\begin{array}{l}\text { Research- } \\
\text { practice gap }\end{array}$ & $\begin{array}{l}\text { Reward system } \\
\text { of academia }\end{array}$ \\
\hline Aguinis et al. (2017) & $x$ & $x$ & & & \\
\hline Aguinis et al. (2018) & $x$ & $x$ & $x$ & & \\
\hline Aguinis et al. (202I) & $x$ & $x$ & $x$ & & \\
\hline Aguinis et al. (2020) & $x$ & $x$ & & & \\
\hline Andraszewicz et al. (2015) & & $x$ & & & \\
\hline Antonakis (2017) & $x$ & $x$ & $x$ & $x$ & $x$ \\
\hline Aguinis and Solarino (2019) & & & $x$ & & \\
\hline Bansal and Corley (2011) & & & $x$ & & \\
\hline Bansal et al. (2012) & & & & $x$ & \\
\hline Barley (2016) & $x$ & $x$ & & $x$ & $x$ \\
\hline Bartunek and Rynes (2014) & & & & $x$ & \\
\hline Baum (20I2) & & & & & $x$ \\
\hline Bedeian et al. $(20 \mid 0)$ & $x$ & $x$ & & & \\
\hline Bergh et al. (2017) & $x$ & $x$ & & & \\
\hline Bettis (20I2) & & $x$ & & & \\
\hline Bettis, Ethiraj, et al. (2016) & $x$ & $x$ & & & \\
\hline Bettis, Helfat, and Shaver (2016) & $x$ & $x$ & & & \\
\hline Bluhm et al. (201 I) & & & $x$ & & \\
\hline Bosco et al. (2016) & $x$ & $x$ & & & \\
\hline Bullinger et al. (2015) & & & & $x$ & \\
\hline Cassell (2016) & & & $x$ & & \\
\hline Cho and Kim (20I5) & & $x$ & & & \\
\hline Cornelissen (2017) & & & $x$ & & \\
\hline Corley and Gioia (201I) & & & & $x$ & $x$ \\
\hline Cortina and Landis (20II) & & $x$ & & & \\
\hline Davis (2015) & $x$ & $x$ & & $x$ & $x$ \\
\hline De Frutos-Belizón et al. (2019) & & & & $x$ & \\
\hline De Man et al. (2020) & & & & $x$ & \\
\hline George (2014) & $x$ & $x$ & & & $x$ \\
\hline Gibbert et al. (202I) & $x$ & $x$ & & & \\
\hline Gioia et al. (2013) & & & $x$ & & \\
\hline Hangel and Schmidt-Pfister (2017) & & & & & $x$ \\
\hline Harley (2015) & $x$ & & & $x$ & \\
\hline Hollenbeck and Wright (2017) & $x$ & $x$ & & & \\
\hline Honig et al. (2018) & $x$ & $x$ & & $x$ & $\mathrm{x}$ \\
\hline Honig et al. (2017) & $x$ & $x$ & & & $x$ \\
\hline Jebb and Woo (2015) & $x$ & $x$ & & & \\
\hline Jonsen et al. (2018) & & & $x$ & & \\
\hline Kieser and Leiner (2009) & & & & $x$ & \\
\hline Kieser and Leiner (2012) & & & & $x$ & \\
\hline Kieser et al. (2015) & & & & $x$ & \\
\hline Kruschke et al. (2012) & $x$ & $x$ & & & \\
\hline Leung (20II) & $x$ & $x$ & & & \\
\hline Lewin et al. (2016) & $x$ & $x$ & & $x$ & $x$ \\
\hline Macdonald and Kam (20II) & & & & & $x$ \\
\hline Mathieu (20|6) & $x$ & & & & $x$ \\
\hline McKee and Miller (2015) & $x$ & $x$ & & & \\
\hline McLeod et al. (2018) & & & & & $\mathrm{x}$ \\
\hline McShane and Gal (2015) & $x$ & $x$ & & & \\
\hline Molina-Azorín et al. (2020) & & & & $x$ & \\
\hline Murphy and Aguinis (2019) & $x$ & $x$ & & & \\
\hline O'Kane et al. (202I) & & & $x$ & & \\
\hline
\end{tabular}


Table 2. (Continued)

\begin{tabular}{|c|c|c|c|c|c|}
\hline Articles & $\begin{array}{l}\text { Scientific } \\
\text { apophenia }\end{array}$ & $\begin{array}{l}\text { Incorrect use of } \\
\text { significance tests/ } \\
\text { interpretation of } p \text {-value }\end{array}$ & $\begin{array}{l}\text { Discrimination } \\
\text { of qualitative } \\
\text { methodology }\end{array}$ & $\begin{array}{l}\text { Research- } \\
\text { practice gap }\end{array}$ & $\begin{array}{l}\text { Reward system } \\
\text { of academia }\end{array}$ \\
\hline Orlitzky (20I2) & $x$ & $x$ & & & \\
\hline Pettigrew and Starkey (2016) & & & & $x$ & $x$ \\
\hline Pratt (2009) & & & $x$ & & \\
\hline Roloff and Zyphur (2019) & $x$ & $x$ & & & \\
\hline Runfola et al. (2017) & & & $x$ & & \\
\hline Schwab et al. (20II) & $x$ & $x$ & & & \\
\hline Shani and Coghlan (20|4) & & & & $x$ & \\
\hline Starbuck (2016) & $x$ & $x$ & & & \\
\hline Starkey et al. (2009) & & & & $x$ & \\
\hline Symon et al. (2018) & & & $x$ & & \\
\hline $\begin{array}{l}\text { Thunnissen and Gallardo-Gallardo } \\
\text { (2019) }\end{array}$ & $x$ & $x$ & & $x$ & \\
\hline Tsui (20I6) & & & & $x$ & $x$ \\
\hline Tsui (20I3) & & & & $x$ & $x$ \\
\hline Tsui and Jia (20/3) & & & & $x$ & $x$ \\
\hline Üsdiken (20I4) & & & $x$ & & \\
\hline Vogel and Homberg (202I) & $x$ & $x$ & & & \\
\hline I. Walsh et al. (20I5) & & & & $x$ & \\
\hline
\end{tabular}

\section{Results: the main flaws of management research}

In this section, we described five basic problems in management research that were identified from the systematic review of the literature. The first three problems are methodological in nature: (a) scientific apophenia, (b) the incorrect use of significance tests and the interpretation of $p$-value, and (c) the "discrimination" of qualitative methodology. The others are more generic and can be considered as core problems, including (d) the research-practice gap and (e) the reward system of academia. The limitations were compiled to synthesize prior findings in the literature and identify the main causes that may hinder the development of responsible science in the management discipline, including the growth of this field of knowledge.

\section{Scientific apophenia in the field of management}

The findings of our review of the literature on criticism in the field of management identified the quality of research as one of the main problems of the discipline, even considering it as a problem that threatens the scientific integrity of the field. Obviously, questionable research practices in the management field put at risk the replication, the falsification of the theory, and the reproducibility of the scientific knowledge generated. This, in turn, indirectly also affects the credibility and impact of the research generated among interested parties and, ultimately, society. However, this is not a recent issue, as the quality of research in the management field has been under attack for more than two decades (Hambrick, 1994). Recent critical voices agree that management research often falls short of the necessary scientific standards of falsifiability, replicability, and data transparency (Barley, 2016; Bettis, Ethiraj, et al., 2016; Cho \& Kim, 2015; Davis, 2015; Gibbert et al., 2021; Honig et al., 2017; Lewin et al., 2016; Starbuck, 2016; Tsui, 2016; Vogel \& Homberg, 2021). Similarly, recent works have yielded a large number of non-replicable findings, including some that have received numerous citations (Ethiraj et al., 2016; Goldfarb \& King, 2016; Vogel \& Homberg, 2021). Replications evaluate the robustness and reliability of a given study by using a different data sample than the original study in a similar setting. Therefore, the publication of only statistically significant results, without the publication of replications of the original studies, results in the inconsistent generation of repeatable scientific knowledge (Bettis, 2012; Bettis et al., 2016; Cho \& Kim, 2015; Goldfarb \& King, 2016; Honig et al., 2018). Goldfarb and King (2016) referred to these practices that infer on the quality of the research generated as the "scientific apophenia" of management research. The term "apophenia" comes from clinical psychology and refers to the consideration of a connection between unrelated or independent elements. Specifically, Goldfarb and King (2016, p. 168) define scientific "apophenia" as the "assigning of inferential meaning when limited statistical power should have prevented such a conclusion or when the data are actually random."

Scientific apophenia and the replicability deficit of research in management have been related in the literature 
Table 3. Some examples of categories and subcategories codified in each of core problems identified in the literature.

Scientific apophenia

Incorrect uses of significance test/ interpretation $p$-value

Discrimination of qualitative methodology

The research-practice gap

Reward system of academia
- $\quad$-Hacking (Aguinis et al., 20I7; Vogel \& Homberg, 2021)

- Harking (Aguinis et al. 2017; Goldfarb \& King, 2016; Murphy \& Aguinis, 2019)

- Incorrect use of control variables (Aguinis et al., 2017)

- Selection of variables in a model (Aguinis et al., 2017)

- Handling of outliers (Aguinis et al., 2017)

- Lack of Transparency regarding data analysis (Aguinis et al., 2018; Thunissen et al., 2019)

- Lack of replication studies (Bettis, Helfat, \& Shaver, 2016; Honig et al., 2018; Roloff \& Zyphur, 2019)

- Lack of methodological rigor (arigorium) (Antonakis, 2017; Roloff \& Zyphur, 2019)

- Presentation of post hoc hypotheses (Leung, 20II)

- Incorrect reporting of p-values (Aguinis et al., 20I7; Bettis, 20I2; Bettis, Ethiraj, et al., 20I6)

- Excessive widespread use of significance test in Management research (Orlitzky, 20I2; Roloff \& Zyphur, 2019)

- Preference for significant results in significance test (Antonakis, 20I7; Orlitzky, 2012; Roloff \& Zyphur, 2019)

- More detailed report on the data and its collection (Aguinis et al., 202I; Bettis, Helfat, \& Shaver, 2016; Goldfarb \& King, 2016)

- To avoid cutting points that reduce the interpretation of the findings (Bettis, Ethiraj, et al., 2016; Bettis, Helfat, \& Shaver, 2016; Goldfarb \& King, 2016; Lewin et al., 2016)

- Lack of Bayesian approaches in management research (Andraszewicz et al., 20I5; Jebb \& Woo, 20I5; Kruschke et al., 20I2; McKee \& Miller, 20I5)

- Misinterpretation of Cronbach's coefficient alpha in the Management field (Cho \& Kim, 20I5)

- Lack of transparency in qualitative research (Aguinis et al., 2018; Aguinis \& Solarino, 2019; O'Kane et al., 2021)

- Evaluate qualitative research from a positivist lens (Bansal \& Corley, 20I I; Bluhm et al., 20I I; Gioia et al., 2013; Pratt, 2009; Symon et al., 2018)

- Higher standards for publishing qualitative research (Bansal \& Corley, 20 I I; Bluhm et al., 20I I; Cassell, 2016; Symon et al., 2018)

- Accept the interpretive subjectivity that characterizes qualitative methodology (Cornelissen, 2017; Symon et al., 2018)

- The particular tendency to quantify qualitative data (Bansal \& Corley, 20II; Cassell, 2016; Cornelissen, 2017; Symon et al., 2018)

- Scholars are not incentivized to collaborate with practitioners (Bartunek \& Rynes, 2014; Shani \& Coghlan, 2014)

- Lack of translation of scientific findings into more accessible media para practitioners (Bansal et al., 20 I2; Bartunek \& Rynes, 20I4; Kieser \& Leiner, 20I2)

- Scholars without bilingual and "bi-competent" skills (Kieser \& Leiner, 20I2)

- Exclusive positivism paradigm in Management research (De Frutos-Belizón et al., 2019; Starkey et al., 2009; I. Walsh et al., 20I5)

- Different logics between scholar community and practitioner community (Bartunek \& Rynes, 2014; Kieser \& Leiner, 2009, 2012)

- Research topics of no interest to practitioners (Bartunek \& Rynes, 2014; Thunissen et al., 2019).

- Management research favorece la publicación de resultados positivos para obtener publicaciones (Antonakis, 2017)

- Management research often favors novelty, whereas replication is devalued (neofilia) (Antonakis, 2017; Barley, 2016; Davis, 2015; Lewin et al., 2016; Mathieu, 2016; Starbuck, 2016)

- Insistence on publishing theoretical contributions (theorrhea) (Antonakis, 2017; Corley \& Gioia, 2011; Mathieu, 2016; Thunissen et al., 2019)

- Scientific publication in top journals as the only key element for advancing one's academic career (disjunctivitis) (Antonakis, 2017; Tsui, 2016)

- Predominance of publication-based performance indicators (Fochler et al., 2016; Hangel \& Schmidt-Pfister, 2017; Ingwersen \& Larsen, 2014)

- Predatory journals of dubious legitimacy and ethics (McLeod et al., 2018)

- Research evaluation without considering the real impact and practical relevance on diverse stakeholders (Barley, 2016; Baum, 2012; Hangel \& Schmidt-Pfister, 2017; Pettigrew \& Starkey, 2016; Tsui, 2013, 2016) to different types of questionable research practices, such as hypothesizing after results are known (HARKing) and data manipulation or dredging ( $p$-hacking). HARKing and $p$-hacking are practices without legitimacy, thereby giving a false appearance to the formulation of wrong predictions (Aguinis et al., 2018, 2020; Bedeian et al., 2010; Bettis 
et al., 2016; Hollenbeck \& Wright, 2017; Goldfarb \& King (2016); Murphy \& Aguinis, 2019; Starbuck, 2016). With practices such as HARKing, unexpected results are reported as if they had been hypothesized in advance (Aguinis et al., 2020; Bosco et al., 2016; Murphy \& Aguinis, 2019; Starbuck, 2016). The "HARKing" practice consists of gathering data first, then performing statistical analyses and then formulating hypotheses. Only at the end of the process does the researcher attempt to identify theoretical foundations or previous works that support or reject the hypotheses just raised (Hollenbeck \& Wright, 2017; Starbuck, 2016). "HARKers" attempt to create the misperception that pre-existing theories have sustained correct assumptions. Obviously, it is completely acceptable to follow an inductive approach and analyze data to identify inferences about systematic patterns and implications. In fact, possible findings that the researcher had previously considered should not be considered. However, a behavior that implies misrepresenting the research procedures by portraying inferences from data as propositions that have been hypothesized before data analysis is a completely illegitimate practice. Similarly, $p$-hacking or data manipulation supposes adulterating the data matrix with multiple calculations or alterations in order to find a determined equation or finding that reflects robust patterns (Bedeian et al., 2010; Starbuck, 2016). These practices can generate false findings that are not replicable. In this way, the researcher can lend false support to theory, making the theory seem more determinative than it actually is (Lewin et al., 2016).

These techniques are clearly encouraged by the greater willingness of academic journals to publish novel studies that generate impact. The research culture and incentive system that prevail in the academy have increased pressure on scholars (Bedeian et al., 2010; Bettis et al., 2016; Starbuck, 2016). According to different studies, the academic incentive system encourages publications in a small number of top journals and often favors novelty over truth in publications, something that has fuelled, in many cases, unreliable research findings (Barley, 2016; Baum, 2012; Davis, 2015; Lewin et al., 2016; Macdonald \& Kam, 2011; Starbuck, 2016). This situation means that some researchers consider choosing between publishing at all costs and advancing their academic careers or the ideals and values for which they were interested in research. Some works suggest that one of the main reasons for this problem has been the preference among management journals to publish "cutting-edge" and "ground-breaking" findings, focusing mainly on positive empirical findings, not demanding reporting or debate of null findings or study of outlier observations, and rarely, considering for publication replication studies (Aguinis et al., 2018; Bettis, Helfat, \& Shaver, 2016; Honig et al., 2018). This confirmation bias is omnipresent in management research (Davis, 2015; Leung, 2011). On the basis of an in-depth analysis, van
Witteloostuijn (2015) concludes that the social sciences, particularly management research, have been unquestionably ignoring basic falsifiability principles, as advocated by Popper (1959). With these actions, scientific journals are giving support to a cynical academic culture of false communication, mediocre scientific standards that support poor and ambiguous theories and ritualistic personnel evaluations.

However, as Starbuck (2016) argues, journals are not the only ones responsible for generating unprofessional and questionable actions. In general, the current academic culture has a certain cynical and careerist nuance, in part because of the specificity of the attributes of research publications used by universities when evaluating the merits of research or advertising faculty achievements. For the researcher, achieving publication in top journals has high priority. The use of indicators and statistical procedures generates a cynical ethos that considers research to be the only way to advance one's academic career. That is, publishing a paper is considered as the means to an end, and ignores the paper's possible usefulness, practical implications, or social impact. In turn, universities compete with one another using the "significant" contributions of their faculty members. Obviously, the selective reporting of hypotheses, and, in short, the use of inappropriate statistical procedures, contradicts the scientific principles of falsification, reliability, and replication as well as the social and ethical value of integrity (Popper, 1959). The socially responsible approach to science requires the joint consideration of epistemic and social values in the development of research. Irresponsible behavior is incompatible with important epistemic values and with society's expectations of honesty in science based on the integrity of research. Furthermore, misconduct is often associated with nonepistemic values closer to self-interest in furthering a professional career.

To work against research misconduct, some works have recently proposed non-demanding and feasible tools that could uncover questionable research practices. Bergh et al. (2017) propose three tests applicable to most empirical analyses and explain and evidence their effectiveness, specifically (a) congruence of statistical tests, (b) simulation of significance, and finally (c) verification based on matrices of descriptive statistics. Other authors insist on the development of actions during the peer-review process to deter this academic misconduct. Specifically, Honig et al. (2018) propose that the peer-review processes should require a "methodological recipe card" that provides detailed information to the reviewers about the empirical analysis and increase transparency. In addition, Honig et al. (2018) propose that journals implement codes of conduct for reviewers and, in turn, encourage authors to provide an evaluation of the review process. These proposals generate a 360 degree peer-review process that improves the perception of impartiality (Honig et al., 2018). 


\section{The incorrect use of significance tests and the interpretation of $\mathrm{p}$-value}

As in many other disciplines, null-hypothesis significance tests are the basis of quantitative empirical research in the management field (Starbuck, 2016). Nevertheless, for approximately 80 years, methodologists have warned of the use of null-hypothesis statistical tests without any apparent success. Researchers have ignored these warnings, continuing to use them even though their interpretations are often erroneous and indicate that the researchers do not understand what the tests indicate (Cortina \& Landis, 2011; Hubbard, 2016; McShane \& Gal, 2015; Orlitzky, 2012; Starbuck, 2016). The $p$-values obtained in these tests do not reflect any information on the rigor and reliability of the findings (Aguinis et al., 2020; Bettis, 2012; Bettis, Ethiraj, et al., 2016; Hubbard, 2016; Schwab et al., 2011; Vogel \& Homberg, 2021).

However, this was another of the findings in our review of the literature on the most-published criticisms of management research. Significance tests are broadly misunderstood, which causes researchers to misinterpret their own data and evidence, and their incorrect use, as well as other dubious research methods, calls into question the standards of falsifiability, replicability, and data transparency in management research. Weak methodology in management research results in unreliable information for the professional world and little usefulness for society.

The dimension of $p$-values is often interpreted as an indicator of the robustness of the results obtained, thus the misinterpretation that small $p$-values indicate stronger or reproducible findings. In the same way, certain cutoff values of the $p$-value $(.05, .01$, and .001) are understood as critical values in testing a hypothesis (Bettis et al., 2016; Goldfarb \& King, 2016; Schwab et al., 2011). This notion causes a specific value of the $p$-value to be interpreted as a border value between truth and irrelevance. Therefore, null-hypothesis significance tests facilitate the empirical demonstration of a concrete fact but can often also erroneously consider unimportant observations as significant or vice versa. The dichotomous treatment given by researchers to the statistical tests distorts the meaning of the $p$-values because there is not a large inferential difference between coefficients with a $p$-value of .04 and another with a $p$-value of .06 , for example. These illusory interpretations do nothing but hinder progress toward a better understanding of relevant social and behavioral processes that take place in organizations. Additional knowledge about the origin of the establishment of the $p$-value cutoff values could contribute to a better understanding of these values and encourage a more prudent and judicious interpretation. The $p<.05$ cutoff was set as a competitive response to certain nonconformities and disputes over book royalties between two reputed statisticians (Goldfarb \& King, 2016). In the 1920s, Kendall Pearson, who was engaged in the sale of extensive statistical tables, was unwilling to allow Ronald A. Fisher to use the tables in his new book. In response, Ronald A. Fisher avoided this barrier by creating a method of inference that was supported only in two values, $p$-values of .05 and .01 (Goldfarb \& King, 2016). Despite this development, Fisher himself later recognized that Pearson's more continuous method of inference was more appropriate and preferable than his binary perspective. Fisher acknowledged that it was more correct to report the $p$-values by refraining from emphasizing the thresholds. This allows the evidence to be interpreted more easily on a continuum and in the context of previous findings. Therefore, one could say that $p$-values are used, to some extent, because in the 1920s a statistician considered that sharing his work could affect his income (Goldfarb \& King, 2016).

In consideration of these practices, journals have proposed new policies specifically aimed at increasing the reliability of the empirical tests of our discipline (Aguinis et al., 2017; Bettis et al., 2016; George, 2014; Lewin et al., 2016; Roloff \& Zyphur, 2019; Starbuck, 2016; Tsui, 2016). By doing so, they implicitly encourage researchers to publish replication studies and null results, giving signals about the possibilities of these outcomes as being accepted. With this shift in approach, journals also encourage purely exploratory research aimed at identifying and describing phenomena. Any statistical analysis could be presented discussing all the findings as positive, negative, or null. As Honig et al. (2018) suggest, journals should also dedicate more publication space to replication studies to recognize their value. According to these authors, more emphasis should be placed on requiring the presentation of replication "road maps" that facilitate future replication work. Similarly, to avoid false positives in empirical tests, different scholars suggest that the authors should provide a more detailed report on the data and its collection, the methodological models used in the research, the experimental conditions tested, or the observations eliminated (Aguinis et al., 2021; Bettis, Helfat, \& Shaver, 2016; Goldfarb \& King, 2016). This reporting allows readers and reviewers to more rigorously evaluate the authenticity and robustness of the reported findings. The implementation of mechanisms that diminish the possibility of finding false positives could also be strengthened, such as randomly dividing the data into two parts before beginning the analysis (Bettis, 2012; Bettis, Helfat, \& Shaver, 2016; Goldfarb \& King, 2016), as random effects will be unlikely to emerge in a second dataset. Meanwhile, Lewin et al. (2016) propose the implementation of preapproval practices. Through these practices, authors present a study proposal where the literature is reviewed and the theoretical basis is explained. In addition, a research question is posed and a data source is proposed, but researchers do not present analyses, the results, or conclusions. Only after the proposal is reviewed and accepted do the authors commit 
themselves to completing the study as previously proposed. In return, the journal would guarantee publication, regardless of the findings finally obtained.

It is likewise advisable to avoid cutting points that reduce the analysis and interpretation of the findings to mechanical rules of borders of false or true to justify scientific conclusions (Bettis, Ethiraj, et al., 2016; Bettis, Helfat, \& Shaver, 2016; Goldfarb \& King, 2016; Lewin et al., 2016). More thoughtful interpretations of test statistics need to be encouraged (Goldfarb \& King, 2016, p. 175). For example, instead of supporting the interpretations of any scientific findings on specific cutoff points, discussions could be developed based on the confidence intervals, explaining the standard errors or the possibilities of obtaining certain results in a dataset and later analyzing the implications for the research proposals or hypotheses established (Bettis et al., 2016).

Some works go even further and have proposed a deinstitutionalization of statistical significance tests that implies an epistemological reform of the research paradigm (McKee \& Miller, 2015; Orlitzky, 2012). This paradigm shift should be based on the abandonment of the idea that the objectivity of a finding depends on the result of a test of statistical significance (Andraszewicz et al., 2015; Kruschke et al., 2012; McKee \& Miller, 2015). Rather, this new paradigm should approach the social construction of knowledge in any social science, characterized by more subjectivist norms and values (Orlitzky, 2012). Once again, the excessive use of statistical significance tests, their incorrect use, or the preferences to publish mainly positive results because they are considered more interesting, showing values that are contrary to the ideas of responsible science. These practices reflect values of instrumentality, opposed to epistemic and social values, turning the "potentially good science into junk science" (Tsui, 2016, p. 14).

As some works have proposed, this implies adopting the ideas of Bayesian approaches to probability that are characterized by a subjective and interpretivist vision of reality and an explicit recognition of probability in the validation of a theory (Andraszewicz et al., 2015; Jebb \& Woo, 2015; Kruschke et al., 2012; McKee \& Miller, 2015). Bayesian estimation is a type of statistical inference that explicitly specifies the probabilities that a hypothesis can be true. That is, the variability or uncertainty in the perceptions of researchers about a hypothesis to be tested, the possible measurement inaccuracies, and, ultimately, the imprecision in the scientific reasoning process is recognized. Bayesian analysis simulates a complete distribution over the joint parameter space under conditions of uncertainty, revealing a range of variation and relative probability of different possible combinations of parameter values. That is, under the use of these methods, rather the probabilities of the hypotheses conditional on the evidence that are known are analyzed. Therefore, in response to the known limitations of the significance tests (effects of small samples, erroneous interpretations, and "null effects") (Andraszewicz et al., 2015; Cortina \& Landis, 2011), the Bayesian statistical inference tests can be proposed as a relevant alternative. However, the known advantages of Bayesian methods still contrast with a dearth of use in the management field (Kruschke et al., 2012).

\section{"Discrimination" of qualitative methodology in the management field}

Recent literature reviews indicate a consolidated trend of growth in qualitative research in the field of management (Bluhm et al., 2011; Cornelissen, 2017; Jonsen et al., 2018; Symon et al., 2018; Üsdiken, 2014). In recent decades, relevant management journals, such as the Academy of Management Journal, have published editorials that encouraged management researchers to develop qualitative techniques that increase the sources of knowledge about organizational phenomena, providing guidelines to evaluate these techniques in the discipline (e.g., Bansal \& Corley, 2011; Pratt, 2009). This growth has been notorious despite the fact that it developed with notable differences between the European context, the American context, and the rest of the world (Bluhm et al., 2011; Üsdiken, 2014). This uneven pace of development is explained, fundamentally, by the differences in terms of epistemological and ontological traditions that have dominated these research contexts (Bluhm et al., 2011; Cassell, 2016). This concern highlights the importance of developing sound scientific methods and processes and giving value to the plurality of methodological techniques without devaluing qualitative methodology. However, as Üsdiken (2014) found in an extensive review, qualitative research represented around $20 \%$ of management research in the last period analyzed. Despite this relatively high presence, we should not be overly optimistic as the recent literature has also highlighted certain barriers faced by researchers conducting qualitative research in the field of management (Bluhm et al., 2011; Cassell, 2016; Cornelissen, 2017; Symon et al., 2018). Furthermore, while this growth is positive and appears to be getting stronger, it may still seem like a low proportion of the research compared with their quantitative counterparts.

Although qualitative techniques have strengths that can be used to provide knowledge in the research field of management, our findings show that there are certain problems related to their development, evaluation, and consequent reliability arising in the research community. Qualitative methodology and its interpretive approach are unique in their ability to describe, interpret, and explain organizational issues. Later in the research process, quantitative methods allow for a description of the prevalence and generalization of the phenomena analyzed (Bluhm et al., 2011). Therefore, qualitative techniques are important to understand business 
phenomena in workers, teams, and organizations and describe their development over time, especially in the field of management research. In fact, multiple well-established theories in the field of management are derived from purely qualitative research (Runfola et al., 2017). However, the logical positivist tradition that prevails in research is the major concern that the research community has about qualitative research in this field. This discipline-dominating research paradigm sets much higher standards for publishing qualitative research compared with quantitative approaches (Bansal \& Corley, 2011; Bluhm et al., 2011; Cassell, 2016; Symon et al., 2018). Yet, these standards evaluate qualitative research from a positivist lens. For this reason, the research community raises concern about the reliability and validity of these standards, and that concern causes them to be marginalized and devalued with respect to quantitative research (Pratt, 2009). This also makes it a less conspicuous research strategy because, in addition to their high demand in terms of field work, they are more difficult to publish. Faced with this difficulty, management scholars opt for the easy route of methodological marginalization that lacks epistemic values found in responsible science. Once again, rewarding academics based on publicationbased performance indicators leads to values of convenience and instrumentality associated with career development. These values cannot be considered as epistemic, social, or even ethical and should never interfere in the methodological decisions of the researcher, since they contradict the scientific principles listed above (Popper, 1959).

There have been attempts in the literature to establish quality criteria that support the evaluation and mark the development of qualitative research (Bansal \& Corley, 2011; Bluhm et al., 2011; Gioia et al., 2013; Symon et al., 2018), but these do not stop imitations of certain purely positivist conventions. The drawbacks are that, in contrast to quantitative methodology, qualitative techniques are supported by a research paradigm characterized by a wide range of philosophical positions (Symon et al., 2018). In this sense, unlike the positivist philosophical consensus that prevails in the discipline regarding quantitative methodology, a standardized pattern for the development of qualitative methodology seems somewhat complex, regardless of whether it is conducive or not. The methodological pluralism offered by qualitative methods offers a wide range of options under which to investigate different research questions, enriching the opportunities to understand organizational phenomena in greater depth.

Possibly, the most recommended quality criterion in the development of qualitative research is transparency (Aguinis et al., 2018; Aguinis \& Solarino, 2019; Bansal \& Corley, 2011; Bluhm et al., 2011; Jonsen et al., 2018; O'Kane et al., 2021). Promoting this detailed and transparent description of the entire qualitative research process, as suggested in some works, aims to provide improved validity, replication, and standardization of these techniques.
For example, Aguinis and Solarino (2019) offer recommendations to improve transparency and replicability in qualitative research. According to the authors, it is necessary to provide specific and detailed information on aspects such as the type of qualitative technique used, the research environment, the position of the researcher with respect to the participants, the sampling procedures or the relative importance of each case. In addition, it is important to provide information on the treatment, and subsequent analysis of the qualitative evidence obtained. For example, the saturation point and the judgments that defined it, the data coding process, and the complete anonymous disclosure of the raw materials (interviews, recordings, transcripts . . .) that supported the study (Aguinis \& Solarino, 2019).

However, we could also argue that quantitative research is not entirely transparent unless we are experts in statistical methodological techniques (Symon et al., 2018). Therefore, this emphasis on transparency in qualitative methodology is based on the little familiarity that some researchers or reviewers may have with these methods, trying to equate these techniques to quantitative methods to gain legitimacy. However, other works have indicated that it is necessary to accept the interpretive subjectivity that characterizes qualitative methodology in the generation of scientific knowledge (Cornelissen, 2017; Symon et al., 2018) without applying purely positivist criteria, such as replication, precision, standardization, or elimination of investigator bias. In fact, the criterion of transparency can be interpreted differently based on the epistemological perspective from which the research is approached. From the perspective of critical theory, transparency would not have to be related to the detailed methodological description but rather to a high level of democratic involvement of the participants in the qualitative study (Symon et al., 2018). Although transparency is understood as a criterion of the positivist tradition, the application of a higher standard of methodological description will not lack benefits if it gives greater credibility to this methodology in our discipline. Therefore, improving transparency standards in qualitative studies is still beneficial and recommended by improving the reliability and possible replicability of the study (Aguinis et al., 2018; Aguinis \& Solarino, 2019; O'Kane et al., 2021).

Instead, we consider it necessary to be critical of the particular tendency to quantify qualitative data. The socalled factor analytic, following the principles of grounded theory, reduces large amounts of qualitative data collected through observations and testimonies, among other sources, into significant factors that explain certain phenomena. With this analytical approach, we try to establish an implicit analogy between qualitative and quantitative methodology that reflects the predominance of quantitative techniques with positivist pragmatism in our discipline (Cornelissen, 2017). However, even appreciating the possible methodological strengths of this trend, this close 
analogy reduces the range of methods and restricts the theorizing styles in our field based on descriptive and interpretive approaches. It would only imply theorizing from qualitative methods from the extraction of constructs that are organized under hypothetical linear relationships. From our point of view, this standardization of qualitative research only leads to the impoverishment of our field itself. This is a concern shared by different works in recent years that see the diversity of methodological approaches endangered (Bansal \& Corley, 2011; Cassell, 2016; Cornelissen, 2017; Symon et al., 2018). We also consider this as detrimental to the richness that the diversity of qualitative methods and their distinctive stamp provide in the generation of detailed explanatory descriptions of organizational phenomena. Paradoxically, greater transparency or quantification of the qualitative methodology can provide greater legitimacy, though it could be negative if it is at the cost of losing integrity and epistemological diversity in our field of knowledge.

On the basis of these statements, we consider that we are in time to develop incremental changes that prevent us from having to reach radical changes in the way knowledge is generated in our field. Cornelissen (2017) stated that an appropriate time to face these problems could be in the postgraduate and doctoral training programs. These programs should provide future researchers in our field with methodological knowledge that addresses, in addition to technical issues, the epistemological roots and the different ways of theorizing that each type of methodology offers. However, we believe the responsibility for preserving this methodological pluralism does not lie solely with qualitative researchers but also with epistemological guardians such as editors and reviewers. If the trends to standardize qualitative methodology are supported by editors and reviewers, then preferences for these trends are implicitly established and could end up being the norm in our discipline. Similarly, journals in our field could designate qualitative researchers as associate editors more assiduously (Symon et al., 2018). In this way, more editorials could be published that initiate discussions of criteria in qualitative methodology instead of suggesting only prescriptive recommendations so that qualitative research is more easily publishable. These publishers should also encourage the development of novel, diverse methodological approaches that avoid the standardization of qualitative research in the field of management. This argument could also be extended to qualitative researchers themselves who must resist movements that impose harmful standardization. Studies that follow less conventional qualitative research designs, such as focus groups, case studies, or critical reviews, contribute to broadening the horizons of qualitative methodology in our field and tend to have a greater impact on the body of knowledge in our discipline (Bluhm et al., 2011; Runfola et al., 2017). Likewise, it would be important to act on the review process, promoting reflexivity about the epistemological paradigm that they apply in their evaluations and honestly regarding the methodological training they may possess. For example, training for reviewers and discussion or mutual learning between reviewer and author could be encouraged (Symon et al., 2018).

\section{Practical relevance in the field of management: "The Valley of Death" between management academics and management practitioners}

The widening research-practice gap, with management research increasingly divorced from the practitioner world, is another key problem of the management field widely recognized by the literature (Bansal et al., 2012; Bartunek \& Rynes, 2014; Bullinger et al., 2015; De Frutos-Belizón et al., 2019; De Man et al., 2020; Kieser et al., 2015; Kieser \& Leiner, 2012; Thunnissen \& Gallardo-Gallardo, 2019). Academics are generally uninterested in the problems of practitioners when framing research questions, and practitioners do not resort to academic research to solve their problems (Bartunek \& Rynes, 2014; Kieser \& Leiner, 2009).

As management was born as an applied field, research was initially focused on solving specific applied problems (Agarwal \& Hoetker, 2007). However, as the literature widely recognizes, at some point in that history, the two communities started to diverge. As noted above, most studies agree that this point has its origin in the publication of reports by the Carnegie Foundation and the Ford Foundation (Gordon \& Howell, 1959; Pierson, 1959), which criticized business schools for the quality of their research outputs because of the lack of scientific content. These critical reports generated "scientification" in the management field and led scholars to develop more rigorous research based on sophisticated empirical analyses (Bartunek \& Rynes, 2014). This "scientification" at the expense of applicability and practical relevance for the professional world could be the origin of the problem that continues today.

Although there is prima facie agreement that the gap exists, there is intense debate about its nature and the reasons behind it. Shapiro et al. (2007) suggests two fundamental reasons that hinder the transfer of scientific research to professionals: lost before translation and lost in translation. Lost before translation refers to the fact that research outputs cannot be translated into practice, because their arguments are previously disconnected by relying on different logics. Lost in translation refers to the problems that arise specifically in the transfer of scientific knowledge to the professional community. The interlocutors do not understand one another because they communicate through different languages. Practitioners fail to read publications in academic journals, as the research they publish is written by researchers for researchers. Research results are not 
normally documented in a way that facilitates application and accessibility to practitioners (Bansal et al., 2012; Kieser \& Leiner, 2009). Bullinger et al. (2015) suggested that researchers prefer producing knowledge, not worrying about translating it and disseminating it to the professional community. Similarly, scholars are more encouraged to publish than to collaborate and engage with professionals (Bartunek \& Rynes, 2014; Shani \& Coghlan, 2014).

The literature has exerted considerable efforts in explaining how the disconnections between academics and professionals should be managed to bring research closer to the needs of professionals (De Frutos-Belizón et al., 2019; Shani \& Coghlan, 2014). Some studies have described the differences and particularities of both communities, arguing that they should relate to one another without crossing their own borders (Bansal et al., 2012; Bartunek \& Rynes, 2014; Kieser \& Leiner, 2012). Management practitioners and academics must develop independently, but they need to form closer alliances to realize the full potential that management research can offer to organizations. If this were to take place, it would be particularly relevant for both of them to inform one another about topics of interest and specific concerns. A key element of this relational perspective would be active listening. Management professionals need to be aware of innovations in management research while academics in this field should listen to professionals, especially in the initial stages of the process, when they are framing research questions. Translating the scientific findings into more accessible media for the professional community could be a good solution. Research translated into informative books may be considerably more influential than journal articles for management practitioners. Publications aimed at practitioners should be steeped in scientific evidence but written for a more general audience, combining interest insights for practitioners as well as scientific findings. However, to establish efficient relationships between both communities, scholars must develop bilingual and "bicompetent" skills. In this way, academics can generate relevant knowledge for the solution of professional problems and, in turn, contribute to the advancement of scientific knowledge in the management field. Academia should, therefore, be able to not only speak the languages of practice and science but also transfer interpretative schemas between the two communities (Kieser \& Leiner, 2012).

By contrast, the growing diversity and specialization of the management field in various areas sometimes lead to a simplification of the complexity involved in the real problems facing companies (Pettigrew \& Starkey, 2016). In fact, the normal thing is that the problems that arise in the companies imply phenomena in multiple areas of knowledge and levels of analysis, but the research mainly focuses on a single level. Therefore, recent works also suggest that not enough attention has been paid in the management field to a multilevel methodological approach (Molina-Azorín et al., 2020), which can offer opportunities to improve and advance in research closer to the reality of business practice.

Other works have also proposed a more pragmatic and interpretive reconsideration of the paradigm from which management research is focused (De Frutos-Belizón et al., 2019; Starkey et al., 2009; Tsui, 2016; I. Walsh et al., 2015). According to these works, it is possible that the adoption in the middle of the past century of a positivism paradigm close to the natural sciences has generated management research that gives greater importance to rigor over relevance. Thus, it is ignored that the social realities studied by management science are completely contextualized by their environment. Assuming a more pragmatic paradigm would deepen understanding, meaning, and action rather than notions related to the description or prediction close to classical positivism. Approached from the same angle, entrepreneurial universities are classified as institutions that play a double relevant role: generating new knowledge and disseminating the said knowledge to society. For some years now, the literature has proposed this idea as one more step in the evolution of the role that universities play in the current knowledge society (Audretsch, 2014; Guerrero \& Urbano, 2012). This new role makes these institutions responsible for generating research and creating mechanisms and institutions dedicated to facilitating the dissemination of newly gained knowledge in society. According to this idea, entrepreneurial universities adopt a completely knowledge-generating approach to solving real problems; relevance and applicability are two guiding values indispensable to this approach (Audretsch, 2014; Guerrero \& Urbano, 2012), values that are much closer to the social values associated with responsible science.

Obviously, all these aims would be much easier to achieve if the incentive system in academia is not based solely on the impact within the academy. This would allow academics to focus beyond simply publishing, therefore fostering greater predisposition to establish relationships with professionals or develop skills that would help transfer the research to the professional world.

\section{The reward system of academia}

The academic reward system and current academic culture of publishing or perishing can be considered as two of the fundamental problems in the field of management because, as we have observed, they influence the problems previously exposed. Likewise, this is a concern that directly and indirectly affects the development of practically all the principles of responsible science. Recent literature has criticized the current emphasis of scholars on publishing, explaining how it determines the behavior of researchers and can be the basis for other problems in our field (Barley, 2016; Baum, 2012; Davis, 2015; Hangel \& Schmidt-Pfister, 
2017; Lewin et al., 2016; Macdonald \& Kam, 2011; Starbuck, 2016; Tsui, 2016).

On the basis of scientific publication as a unit of recognition, in the late 1950s, Robert K. Merton (1957, 1973) developed the notion of a reward system of science based on peer reputation. As Merton (1957, p. 642) suggested, "the institution of science has developed an elaborate system for allocating rewards to those who variously live up to its norms." According to him, the concept of recognition can be understood in general terms as "the giving of symbolic and material rewards" by scientific peers (Merton, 1973, p. 429).

There is no doubt that scientific publications must provide an accessible knowledge base that allows for a constructive exchange of knowledge among researchers. However, in the current academic culture where there is intense competition for measurable successes, academics have become irremediably focused on publishing while adapting to the contemporary publish-or-perish culture. Academics are evaluated on the basis of their publications in top journals, considering almost exclusively the "journal impact factor" (JIF). Therefore, those who want to be rewarded orient their work toward the standards and research topics defined by the agenda of these journals (Corley \& Gioia, 2011; Davis, 2015; Starbuck, 2016; Tsui, 2016). The recent literature agrees with the criticism that management research often favors novelty, whereas replication is devalued (Barley, 2016; Davis, 2015; Lewin et al., 2016; Mathieu, 2016; Starbuck, 2016). Most management scientific journals expect the articles they receive to make some theoretical contribution, which has caused an obsession in many scholars to develop and publish theory at all costs (theorrhea) (Antonakis, 2017; Corley \& Gioia, 2011; Thunnissen et al., 2019). Davis (2015) criticized management theory for prioritizing and valuing the superiority of novel knowledge, rare and curious findings, and questionable and counterintuitive findings over "truth" as well as the accumulation of rigorous knowledge. Barley (2016) also suggested that this circumstance is intensified by the way in which $\mathrm{PhD}$ students are trained, the criteria for choosing manuscripts by journal editors and reviewers, and the rewards policies that award positions and promotions. In the academic world, career incentives have distorted the final goal of the publications because they are perceived as a key element for advancing one's academic career, something that is not always compatible with scientific rigor and ethical behavior (Tsui, 2016). Einstein's theory of relativity superseded Newtonian mechanics because it better explained the observed reality and not because it represented a novel, counterintuitive, or provocative knowledge (Tsang, 2016).

Different scholars have suggested that the predominance of publication-based performance indicators, such as JIFs or Hirsch (h)-index, determine the conduct of academics and foster a behavior determined by obtaining numerous publications of measurable value (Fochler et al., 2016; Hangel \& Schmidt-Pfister, 2017; Ingwersen \& Larsen, 2014). This is what is known as reactivity, which refers to how actors respond to the circumstance that their actions are being evaluated and alter their behavior to improve the performance of their evaluation (Fochler et al., 2016, p. 178). If academics are valued fundamentally for their output in terms of publications, then a high percentage of their behavior will be directed to that output for which they are valued. Hangel and Schmidt-Pfister (2017) recently analyzed the motivations for research throughout the different stages of the academic career. The authors concluded that, "the tension between wanting and having to publish reveals a shift from publishing to a consequence of getting interesting research results, to doing research in order to publish" (Hangel \& Schmidt-Pfister, 2017, p. 541). These findings suggest a general perception that obtaining publications is the conditio sine qua non, regardless of the stage in the academic career. The decoupling between career incentives or rewards and the development and progress of our field can be the source of multiple disruptions. It is considered that the quantitative indicators used to evaluate academic performance can replace deeper considerations regarding quality and scientific rigor as well as the attention on possible practical and social implications of the generated knowledge. This culture has come to question the knowledge base of science, that is, the reliability of the findings (Fanelli, 2012). As Nosek et al. (2012, p. 616) observed, "to the extent that publishing itself is rewarded, then it is in scientists" personal interests to publish, regardless of whether the published findings are true. The rewards that guide the academic career based on "impact" (citation counts) and "productivity" (article counts) is actually a perverse incentive system that fosters the appearance of many questionable research practices (Bettis et al., 2016; Goldfarb \& King, 2016). This context has even fostered the increasing appearance of predatory journals of dubious legitimacy and ethics that potentially influence measures of scientific productivity (McLeod et al., 2018).

Management scholars focus their research on topics of interest to the scientific community, which could be easily publishable, and answer questions posed from the academic world of management. In this context, books, chapters, and reports are research outputs that are worse considered and often undervalued compared with publications in scientific journals. This situation causes the excessive use of citation-based metrics to feed a perspective directed exclusively to the academic audience and consolidates the tendency toward specific and exaggerated scientific writing style. As Tsui (2016, p. 17) suggested with a quite critical tone, management research has become "an annual pageant show with multiple judges rating schools on teaching and research, using criteria that are observable and countable to achieve some degree (or semblance) of 
objectivity." The current reward system of publicationbased performance indicators limits the autonomy of scholars when it comes to selecting the most appropriate medium to disseminate their research. Values associated with responsible science are far from the values that are more closely linked to success and individual reputation in academic publishing. Obviously, the scientist responsible for the research is the best judge of the most appropriate medium for their research and their audience. However, in this final stage of their research, they must incorporate social values to ensure the greatest possible success of their research, and so, according to the ideas of responsible science, something similar must occur at the beginning of the research process, where social values must play a key role in guiding scientists on their choice of research project. This would guarantee that management research is of service for real and relevant problems in society, instead of fundamentally looking for "theoretical gaps" in the literature (Davis, 2015; Suddaby, 2014).

In response to these problems, the nonuse of journal quality standards as a scientific quality indicator has been specifically suggested (DORA, 2012). Similarly, in 2015, Nature published the Leiden Manifesto for research metrics, in which a series of principles that aim to improve evaluation practices in science was exposed (Hicks et al., 2015). This manifesto strongly criticizes the interpretation and use made of bibliometric indicators when evaluating scientific performance. In this same more extreme approach, some papers have even suggested modifying the academic journal system as a whole. Specifically, they propose "open post-publication peer review" (George, 2014; Osterloh \& Frey, 2020). Under this system, a paper is published online and several reviewers can publicly comment on the document. This approach generates transparency, fostering a plurality of opinions. Other less drastic proposals suggest that scientific journals, in addition to providing information on the JIF, should also provide public information on the possible skewed distribution of citations (Osterloh \& Frey, 2020). This provides information on highly cited articles that may distort the impact factor of the journal. To avoid these possible problems, bibliometric indicators could be developed at the article level. This proposal is based on research being evaluated according to its rigor and scientific content, regardless of the scientific journal in which it is published.

However, we consider it necessary to move a step further in these measures. Definitely, it seems both intriguing and troubling how our reliance on such flawed measures to judge and evaluate our research performance is escalating. According to Goodhart's law, when a performance indicator becomes an objective or a goal for the individual, it loses its meaning and stops functioning as a measure (Varela et al., 2014). Fochler et al. (2016) argued that the highly individualistic dynamics fostered by the current academic reward system are likely to challenge the social commitments of the scientific community. It is problematic that academics are systematically motivated to focus their objectives above what is necessary to build and consolidate collective and collaborative knowledge structures. Synthesizing and reducing the scientific system to a regime of rewards and valuation could also distance academic science from social values and needs (Tsui, 2016). This finding implies that the science and research concerned and focused on performance-oriented concerns rather than on social outcomes or values run the risk of hindering their epistemic development. Therefore, a correct evaluation of research in our field should consider the effective impact and practical relevance on diverse stakeholders, specifically considering the importance of these practical implications for the professional world and society. When the scientific quality of work is evaluated solely in terms of impact on the scientific community, it does not consider the social values to which any scientific research must respond. The scientific community may use epistemic values to evaluate quality of work, but the usefulness of scientific knowledge in the context of application must be considered for its true quality to be understood. Therefore, it is not just a question of dispensing with evaluations of scientific quality based on quantitative key indicators, such as the number of publications, the number of citations, the journal's impact factor, or the scholar's h-index, but rather the changes in performance assessment metrics or academic reward systems that would more accurately assess the impact of research on stakeholders and the particular importance of the research for business and society. This means evaluating scientific knowledge for its contributions to society instead of just internal scientific values. Assessing the impact will require the dissemination of findings to nonacademic circles and going further by monitoring whether the business world, society, and policymakers benefit from the scientific knowledge generated (Hemlin \& Rasmussen, 2006; Lebel \& McLean, 2018; Rousseau et al., 2008). For example, the approach of entrepreneurial universities to which we have previously referred places these institutions as in charge of generating research areas, mechanisms, and institutions dedicated to facilitating the dissemination of the knowledge generated to society (Audretsch, 2014; Guerrero \& Urbano, 2012). In this sense, we suggest that the possible reviews of research evaluation should follow a more holistic orientation to identify the contextual factors that facilitate a multidimensional vision of impact and quality. For example, Lebel and McLean (2018) propose the development of additional performance indicators such as Research Quality Plus. This indicator recognizes the fundamental position of stakeholders and users to define whether research is relevant in their context of action.

However, although most reward systems are focused on publication-based performance indicators, it is important to consider the autonomy that universities have regarding 
the application and modification of these systems. The reward system models present in the academic world are criticized beyond both discipline and national borders (Fochler et al., 2016; Hammarfelt \& De Rijcke, 2015; Hangel \& Schmidt-Pfister, 2017). These models are widely distributed throughout multiple academic contexts, and are found, more specifically, in Europe (Fochler et al., 2016; Hammarfelt, 2017; Hammarfelt \& De Rijcke, 2015), Australia (Butler, 2003), the United States (Espeland \& Sauder, 2007), and Asia (Quan et al., 2017). However, in many European countries, academic reward systems are directly dependent on government rules or public policies. Therefore, political issues, and even the political model that characterizes each country, can also determine the approach of these reward systems and their method of application. For example, the model in Anglo-Saxon countries tends to follow an approach closer to laissez-faire neoliberalism. This model downplays intervention and gives universities great autonomy when establishing their own reward systems. On the contrary, there are models that include public intervention from the ideals of traditional and modern socialism. These models, found in countries such as Spain, Portugal, and France, are characterized by being more normative and regulated since they clearly establish the academic career paths and reward systems. Therefore, in addition to considering possible changes in the reward systems and the development of additional performance indicators, we cannot forget the role of public policy in the development of academic careers.

Obviously, all these possible proposals demand a transformation of the academic reward system that involves multiple levels, including governments, universities, journals, editors, reviewers, and academics. As Barley (2016, p. 4) argued, "it is time for us to agree on a procedure that stresses quality of contribution over the reputation of a paper's outlet or the number of citations it receives."

\section{Discussion: the winding roads to explore}

Developing a critique of a research body is relatively easy as long as an alternative is not presented. In this work, we have displayed a set of problems that must be addressed if our field of knowledge wants to develop responsible and rigorous research (Table 4). Therefore, the purpose of our discussion was to analyze the role of values in the research generated in the management field. Based on the previous analysis of published criticisms of management research and from the ideals of socially responsible science (Brown, 2013; Bryman, 2016; Tsui, 2016), we expose how research in the management field is impregnated with social and political values, undermining the objectivity and quality of the scientific knowledge generated in the field. In line with these works, we encourage the transformation of the management research field by considering both epistemic and social values, recognizing the mutual dependency between science and society and fulfilling the criteria of both rigor and relevance. We then intend to propose a roadmap to guide possible revisions in the management field.

Epistemic and social values can be differentiated according to the classification of science-related values (Bryman, 2016; Douglas, 2009; Tsui, 2016). Epistemic values are related to cognitive norms and standards that guarantee sound science and are used to judge the sufficiency of a theory or evidence. With social values, we refer to values that are not related or relevant to the purely scientific activities that lead to the generation of knowledge. These non-epistemic values include ethical dimensions that can influence the researcher's decisions in specific points of the scientific process, for example, when evaluating practical implications or assessing the assertion of evidence (Tsui, 2016). Therefore, it could be considered that they would include moral and political aspects or standards about what we should do. Therefore, while they are not internal to science itself, they would condition scientific behavior. Scientific activity implies the inevitable application of personal values or value judgments when carrying out research activities (Brown, 2013; Douglas, 2009). Both epistemic and social values are relevant to achieve what could be defined as responsible science. In fact, value-free science would not make sense because the research process itself is influenced by values, from the choice of the research topic to the selection of research dissemination channels. In addition, science without values is not desirable as it must be at the service of society (Bryman, 2016). However, this has not always happened in the field of management. The fundamental objective of management research is to improve understanding and clarify empirical puzzles in the business world. Therefore, practical relevance in a purely applied field is indispensable (De Frutos-Belizón et al., 2019). Management is a field laden with epistemic values and, therefore in turn, with social values. However, these social values that make up our field have not served to bring our scientific field closer to society but rather to move it further away (Tsui, 2013, 2016). The critical judgments we have collected throughout our work help explain why. We have completely excluded the users of our research from the evaluations of our knowledge. Academic reward systems and academic evaluations of research have generated a greater disconnection with business and society. On one hand, management academics, due to our status as knowledge authorities, have the responsibility to apply epistemic values that lead us to minimize scientific errors and, on the other hand, respond to real problems with confinable knowledge containing relevant implications for practice through the application of positive social values (Tsui, 2016). 
Table 4. Concerns in management science and possible solutions.

\begin{tabular}{|c|c|c|}
\hline Concern & Definition & Consequence \\
\hline Scientific apophenia & $\begin{array}{l}\text { The assigning of inferential } \\
\text { meaning when limited } \\
\text { statistical power should } \\
\text { have prevented such a } \\
\text { conclusion or when the data } \\
\text { are actually random }\end{array}$ & $\begin{array}{l}\text { Questionable } \\
\text { and poor } \\
\text { methodological } \\
\text { research practices } \\
\text { (HARKing and p- } \\
\text { hacking) }\end{array}$ \\
\hline $\begin{array}{l}\text { Incorrect use of } \\
\text { null-hypothesis test }\end{array}$ & $\begin{array}{l}\text { A specific value of the } p \text { - } \\
\text { value to be interpreted as a } \\
\text { border value between truth } \\
\text { and irrelevance }\end{array}$ & $\begin{array}{l}\text { Researchers to } \\
\text { misinterpret their } \\
\text { own data and } \\
\text { evidence }\end{array}$ \\
\hline
\end{tabular}

The crisis of qualitative methodology in the Management field
The Valley of Death between academics and practitioners

Academic reward systems
Evaluation of qualitative research from a positivist lens; lack of quality criteria

Lack of connection between academics and professionals in the Management field

Predominance of publication-based performance indicators
Possible solutions

- Three tests applicable to most empirical analysis (Bergh et al., 2017)

- "Methodological recipe card"

- $360^{\circ}$ peer-review process (Honig et al., 2018)

- Encourage replication studies and purely exploratory research (Antonakis, 2017; Honig et al., 2018; van Witteloostuijn, 20I5)

- More detailed report on the data and its collection and methodological issues (Goldfarb \& King, 2016; van Witteloostuijn, 20I5)

- Randomly divide the data sample (Bettis, 2012; Goldfarb \& King, 2016)

- Preapproval practices (Lewin et al., 2016)

- Discussions based on confidence intervals (Bettis et al., 2016; van Witteloostuijn, 2015)

- Bayesian methods (Andraszewicz et al., 20I5; Jebb \& Woo, 2015; Kruschke et al., 2012; McKee \& Miller, 2015)
Devaluation of qualitative research versus quantitative techniques
Scholars generate academic research fails to address the practical issues that professionals face in organizations

Contemporary publish-or-perish culture
- Promote methodological transparency in the development of qualitative techniques (Aguinis et al., 2018; Aguinis \& Solarino, 2019; Bansal \& Corley, 20I I; Bluhm et al., 20II; Jonsen et al., 2018; O'Kane et al., 202I)

- Accept the interpretive subjectivity that characterizes qualitative methodology in the generation of scientific knowledge (Cornelissen, 2017; Symon et al., 2018)

- Avoid the standardization of qualitative methodology through the quantification of qualitative data (Bansal \& Corley, 20I I; Cassell, 2016; Cornelissen, 2017; Symon et al., 2018)

- Improve the methodological training of future researchers in postgraduate and doctoral training programs (Cornelissen, 2017)

- Multilevel methodological approaches (MolinaAzorín et al., 2020)

- Reconsideration of the paradigm of science in the Management field (Starkey et al., 2009; Tsui, 2016; De Frutos-Belizón et al., (2019))

- Incentivize scholars to carry out interactions with professionals and companies (Vosburgh (In press))

- Avoid the use of journal quality standards as a scientific quality indicator (Alberts, 20I3; DORA, 2012; Hicks et al., 2015)

- Open post-publication peer review (Kriegeskorte, 2012; Osterloh \& Frey, 2020)

- Provide public information on the possible skewed distribution of citations (Osterloh \& Frey, 2020)

- Bibliometric indicators at the article level

- Consider the effective impact and practical relevance on diverse stakeholders (Author, 2019; Hemlin \& Rasmussen, 2006; Rousseau et al., 2008).

- Development of additional performance indicators (Lebel \& McLean, 20I8) 
The research calls on a specific topic that should reveal the social values of the scientific communities and the demands of policymakers, the business world, and society. The use of these values to guide the choice of a research topic should be encouraged if the topics meet the needs of society (Bryman, 2016). However, in our field, most academics search their own literature for "theoretical gaps" (Bansal et al., 2012; Davis, 2015) instead of focusing their research on the needs of the real world. Researchers, instead of entering new topics, prefer to respond to topics of interest to the scientific community, which are more easily publishable. In the choice of topics to investigate, social values should undoubtedly play an important role. In this way, we are guaranteed to put science at the service of the problems important to society. Collaborative approaches between communities of academics and professionals have been proposed to bring both groups together in the initial stages of research (Shani \& Coghlan, 2014). In the same way, the professional association for each discipline should help identify the "grand challenges" in the world of practice (Tsui, 2016). Nevertheless, we must consider that the social demands for business research go beyond strictly managerial problems. We cannot be a field that focuses its research only on the benefit of organizations (Tsui \& Jia, 2013; J. P. Walsh et al., 2003). Different works argued that our field should also face current issues of social importance, such as poverty, social inequality, job insecurity, corporate corruption, global warming, or the sustainability of natural resources (George et al., 2016; Stahl et al., 2020; Tsui, 2016; Tsui \& Jia, 2013).

The criteria to select research topics based on publication chances have also caused the field of management to emphasize the construction of theory. As Birkinshaw et al. (2014) argue, fetishistic theory is generated largely as a reply to the growing career pressures to publish, and it refers to theory that has become ritualized, mechanical, artificial, and largely derived from parsing texts rather than empirical experience. Management theories have also been divorced from empirical riddles, something that contributes to the research-practice gap, since research in management has reified theory as the research focus par excellence, thereby separating it even more from the professional community (Bansal et al., 2012; Bartunek \& Rynes, 2014; Corley \& Gioia, 2011). Similarly, the search for easy publication can lead to questionable research practices that seek to satisfy the standards imposed by the journals on the novelty of results (Davis, 2015; Goldfarb \& King, 2016). As Tsui (2016) argues, these research practices reflect values close to opportunism, convenience, careerism, or personal interests. These are values not referred to as either epistemic or sociological but as negative "social" values that can transform potentially relevant science into junk science (Bryman, 2016). Therefore, the problems generated by theory fetishism and unreliable, invalid, research practices must be identified from the initial review processes. However, the literature has also suggested that revision is plagued with problems that are based on the prevalence of negative social values during the evaluation of science (Bedeian, 2004; Starbuck, 2016; Tsui \& Hollenbeck, 2009). Alternative solutions on a large scale could be drawn because of the emergence of the "code of ethical behaviours" (Crane \& Matten, 2016; Tsui, 2016). The proliferation of these codes during the formation of future $\mathrm{PhD}$ could guarantee the use of epistemic values and the proper application of social values during the research process. In the management field, different associations, such as the Academy of Management, the Academy of International Business, the European Academy of Management, and the International Association for Chinese Management Research, have similar codes; however, these codes are too general (Tsui, 2016). As Tsui (2016) argues,

the community of scholars in the school disciplines jointly could develop a list of epistemic, cognitive, social, and ethical values that are relevant in the pursuit of science, [...] defining the values appropriate at each stage of the scientific process, and clarifying the role of each type of values, either directly or indirectly. (p. 18)

Similarly, we should not question that management science, as a social science, is full of social values. Management scholars have the responsibility of guiding business actions toward a prosperous and sustainable socioeconomic context. To do so, research in management should adopt a more pragmatic vision and reflect on how organizations and their management are transforming our society. To obtain legitimacy as a scientific discipline, management research adopted a positivist approach based on natural sciences. This empiricist approach generated an obsession with the rigor concerning the relevance that has not always allowed for confronting real-world problems effectively (De Frutos-Belizón et al., 2019; Starkey et al., 2009). The discipline is excessively focused on the principles of verification, trying to demonstrate positive aspects. With this approach, we violate Popperian postulates about scientific progress (van Witteloostuijn, 2015). This obsession has inadvertently encouraged the use of poor research practices as well (Goldfarb \& King, 2016). Paradoxically, positivist science postulates the "ideal free-value" in the development of research to protect and isolate scientific work from possible social values. However, the management field is a social science contextualized in the social phenomena that take place in organizations (Tsui, 2016). Social sciences must deepen the analysis of the social patterns involved in human behavior. A more pragmatic and responsible approach to management research admits the importance of epistemic and social values to guide relevant and ethical science. In our view, the adoption of a research paradigm close to the natural sciences in a social 
science has questionable implications (Mohrman \& Lawler, 2011). A scientific model based on positivism creates the idea that the social realities involved in the study of organizational performance could be predicted through exact science, ignoring that social realities are completely conditioned by the environment in which the object of study is contextualized. Therefore, a more pragmatic and interpretive reconsideration of the paradigm from which management science is focused must be carried out (Starkey et al., 2009; Tsui, 2016). It is necessary to develop investigations based on an assumption of a more democratic paradigm, where the researcher is integrated into the object of study and creates links with organizations to enrich practical relevance (Banks et al., 2016). The model followed by other disciplines, such as the "science of the artificial," anthropology, or environmental sciences (De Frutos-Belizón et al., 2019; Hodgkinson \& Rousseau, 2009; Starkey et al., 2009), could help to overcome this trend. Similarly, this empiricist research trend has conditioned the research questions that have arisen and devalued other research modes (Harley, 2015). Even if the value added by the positivist approach to the progress of our field is unquestionable, it should not become the only dominant research model (Harley, 2015). We should not believe that this approach is above the rest or is the most legitimate research position. In this sense, development of more exploratory studies in our field should be encouraged, which should be the basis for further positive estimations (Hollenbeck \& Wright, 2017). Likewise, it is important to combat the mistaken belief that distrusts qualitative research findings (Wright, 2017), because it makes them significantly less cited and considered by scientific journals (Antonakis, 2017). Clearly, academics themselves have an important role to play in the publication and implementation of alternative research modes. However, this reorientation of the paradigm is unlikely to come from academics in the early stages of their academic career, given that they have to follow the "rules of the game" imposed. Instead, professors in tenured positions could inspire these transformations by forming new $\mathrm{PhD}$ students in more democratic and participatory foundations that underpin the philosophical principles of the social sciences. Publishers, through their editorial policies, could also challenge the dominant status of the positivist approach and support a greater pluralism of research perspectives in our field (Harley, 2015).

A final problem refers to the use of media to disseminate research results. Journal publications are the main element with which to judge the scientific performance of researchers in the field of management (Baum, 2012; Davis, 2015; Hammarfelt, 2017; Hangel \& SchmidtPfister, 2017; Lewin et al., 2016; Macdonald \& Kam, 2011; Starbuck, 2016). This has meant that certain research outputs such as books, book chapters, or papers in lowertier journals are undervalued and even discarded (Tsui,
2013, 2016). Today, researchers focus their efforts on obtaining publications in high-level journals to advance their careers. As Tsui (2016) asked, what values encourage academics to publish following these canons, and why has the investigator chosen the media to diffuse his or her research? Academics perceive publications as an element to compare themselves with others in terms of their quality and prestige as researchers, though it has been confirmed that current quantitative metrics do not reflect the real quality of the articles in these high-level journals (Baum, 2012; Macdonald \& Kam, 2011; Osterloh \& Frey, 2020). Academic rewards based on impact factor, citations received, and number of items make up a perverse incentive system, leading to the questionable research practices (Bettis et al., 2016; Davis, 2015; Goldfarb \& King, 2016). There is an indisputable need to review the evaluation of scientific performance by the academic community and research funders. A reorientation of paradigm assumptions in management science toward more pragmatic approaches involves more democratic and participatory research (De Frutos-Belizón et al., 2019). More involvement on the part of all intervening agents is necessary. Other fields of research have made incipient efforts in this sense, such as the San Francisco Declaration of Evaluation of Research during the Annual Meeting of the American Society of Cellular Biology in San Francisco, CA, 16 December 2012. In this statement, a group of reviewers and editors developed a criticism based on the cessation of metrics derived only from publications of high impact factors. By questioning the evaluation and incentive systems, management research could foster the integrity and reliability of science, thus complying with both epistemic and social values. The research dissemination stage must contain as many social values as the choice of topics to investigate. If we do not discriminate our research correctly to target audiences, then it will be difficult to solve real problems. The researchers themselves must be the best judges to decide in which way and where to disseminate their research findings according to the research domain and its potential readers. Therefore, scientific achievements should be based on the importance of the ideas and the quality of the knowledge generated and not on where the work is published.

\section{Conclusion}

With this work we have wanted to shed light on the problems of research in the field of management by reviewing the previous criticisms in the literature. As we saw in the literature, there are multiple critical examples that have identified various deficiencies suffered by research in the field of management. However, these criticisms represent an unstructured field. Most criticisms have focused on certain unrelated concerns from different reflections, editorials, or position articles. Based on these limitations, our 
work provides the literature with a complete background on the main problems of the discipline that must be addressed to promote the transformation of research in management to meet both scientific rigor and social relevance. Therefore, this work contributes to the consolidation of critical knowledge in this field, structuring the literature and proposing a classification of the fundamental problems on which to act.

The review of the literature and the synthesis of the main criticisms about the research in the management field also allowed us to reach relevant conclusions. As we have seen, the first three problems are methodological in nature: (a) scientific apophenia, (b) the incorrect use of significance tests and the interpretation of $p$-value, and (c) "discrimination" by qualitative methodology. We identified multiple papers in the literature review that criticized the management field for important deficiencies in its compliance with scientific methodological standards. The current reward system supports the culture of "publish or perish," so achieving publication in top journals has high priority for a researcher. Furthermore, as some studies suggest, management journals show a preference for publishing positive empirical findings, do not demand reporting or debate of null findings or studies of outlier observations, and rarely consider replication studies for publication (Honig et al., 2018). Therefore, in trying to achieve the maximum number of publications in top journals, academics violate certain standards of falsifiability, replicability, and data transparency to meet the conditions set by journals. Falsifiability or lack of methodological transparency are not justifiable; however, "reactive" behavior and its result is understandable in this context: if academics are valued fundamentally for their output in terms of publications, then a high percentage of their behavior will be directed to that output for which they are valued and they will show a preference for publishing topics and results that are more publishable. In the management field, a positivist logical tradition prevails that establishes much higher standards for qualitative research compared with quantitative approaches in publishing papers (Bansal \& Corley, 2011; Bluhm et al., 2011; Cassell, 2016; Symon et al., 2018), which means that researchers will prefer quantitative analyses in their research to enjoy higher legitimacy and probability of being published. Similarly, another of the core problems in the management field is (d) the research-practice gap, which has the most attention in the literature. The knowledge gained by academics in the management field is often criticized because of its reduced relevance to practitioners. Again, relevant conclusions can be reached that could generate a counterpoint that is the subject of discussion. The academic reward system does not generate favorable conditions for academics to focus their research on professional demands, since academic rewards are fundamentally aimed at obtaining publications in top journals. Scholars prefer to produce knowledge and not worry about translating it for and disseminating it to the professional community and so devalue other dissemination channels such as books or book chapters. For this very reason, scholars choose research topics that primarily arouse interest in the academic community. These arguments are debatable if we talk about academics who are at more advanced stages in their academic careers and who have more autonomy to carry out collaborative projects with the professional community. However, publishing may be considered a conditio sine qua non across all career stages since publication-related performance indicators are the evaluation basis for funding of European research projects. Furthermore, strong publication pressure reduces intrinsic motivation in academics in the early stages of their careers (Fochler et al., 2016; Hangel \& SchimidtPfister, 2017), and their behavior is strongly influenced by research evaluation policy (Hammarfelt \& De Rijcke, 2015).

Therefore, the analysis of the results of the review suggests that the main concerns in the management field share a common denominator, (e) the academic reward system that conditions the development of research and causes tensions and barriers that create the research-practice gap. This is the fifth core problem that we identified in our review. As explained above, if we analyze each of the previous problems, the academic reward system is a core problem that indirectly causes the appearance of other problems. Therefore, starting from this premise, and after analyzing the reasons underlying each of the identified problems, we reflect on possible subjects of a broader, open, debate in the development of future work.

First, in one way or another, the model implemented by the various national science systems is characterized by the evaluation of quantitative key indicators such as the number of publications, the number of citations, the journal's impact factor, or the scholar's h-index (Fochler et al., 2016; Hammarfelt \& De Rijcke, 2015). Perhaps changes in performance assessment metrics and academic reward systems would increase focus on the assessment of the positive impacts of research on diverse stakeholders and thereby recognize their particular importance for business and society. These ideas were presented early on by Hemlin and Rasmussen (2006), who proposed research evaluation in the context of the application of results; the legitimacy of scientific knowledge must be evaluated not only for its internal scientific values but also for its contributions to society. If science is at the service of society, scientific knowledge must be evaluated by academic experts and, in a complementary manner, by all other stakeholders. In this way, rigor and social relevance would be guaranteed. Some countries have already taken note of these initiatives, and more research and evaluation funders are considering social impact as a basic criterion in evaluation procedures. For example, as of 2021 in the United Kingdom, the Research Excellence Framework (REF) (a 
system for assessing the quality of research carried out by British universities) will include social impact and public commitment as one of its three main evaluation criteria (Watermeyer \& Chubb, 2019). Likewise, in the evaluation of funding for European research projects, a third of the application will depend on the detailed information provided regarding the social impact and relevance of the project.

As mentioned previously, it is also important to consider the political issues that influence the approach of scientific public policy and national science system models (Sam \& Van Der Sijde, 2014). These political perspectives often determine the degree of autonomy of the different national science systems that establish the academic rewards. For example, Anglo-Saxon countries tend to follow an approach closer to laissez-faire neoliberalism, while other European models (such as France, Spain, and Portugal) are characterized by being more normative and regulated. This not only affects the freedom and autonomy of the universities but reflects the social orientation of the state. For example, Nordic countries have a clear social orientation in their policies. Therefore, it would be interesting for future works to analyze the implications of state intervention and cultural and political issues, with the objective of putting science at the service of society. Comparative studies between the different academic models could begin an interesting debate in the literature on this matter.

However, even though, as we argue, the current reward system can be considered as a central problem that conditions the behavior of academics, the academic world should not fall into inaction. As we have seen in the previous discussion section, these problems pose great challenges for the academics in the discipline that would require deep changes in the academic culture of the field. Explicitly addressing these challenges could help us to develop our field from the idea of responsible science, fostering epistemic values that guarantee the quality and integrity of the knowledge generated. The acknowledgment of social values would also provide relevance to the research generated, favoring its applicability and social contribution. In fact, some initiatives and efforts have already been launched. Good examples of this are the development of specific journals to address professional topics for a practitioner audience, such as, Academy of Management Perspectives, Academy of Management Discoveries, and Human Resource Management. Likewise, relevant associations to bridge the science-practice gap have been created from the academic world. An example of this is EurOMA, or the Network for Business Sustainability (NBS). EurOMA, for instance, is an international network of academics and practitioners with a common interest in the continuing development of Operations Management. EurOMA provides members with tools and forums to share their ideas, knowledge, and experience about people-related aspects of Operations Management. NBS defines itself as a boundary-spanner and intermediary organization, and it employs a rigorous process designed to identify relevant academic knowledge and synthesize the findings for a practitioner audience.

However, despite the efforts made so far, we must be aware that there is still a long way to go to develop the necessary changes. As we have argued in our discussion, the ideas of responsible science and a more interpretive and less positivist research paradigm shift could help bring the discipline of management closer to real problems. There are many challenges and social demands to face beyond the needs of the professional world. A researcher should not consider that the ultimate goal is scientific publication. The management field is at the service of society. The relevance of management research goes beyond just the managerial profession, as it also has social implications. As we argued at the beginning of our work, it could be considered that management scholars have a great opportunity with their research to guide business actions toward practices closer to a prosperous and sustainable socioeconomic context.

By contrast, efforts should not be solely focused on the academic world. Changes of such magnitude that they involve putting science at the service of society require modifying incentive systems at all levels (governments, universities, journals, editors, reviewers, and academics themselves). It is time for incentive systems to reward and incentivize interactions and collaborations with the professional world and not only consider quantitative indicators related to top-tier journal publications. The management field, as an academic discipline, has much to learn from other fields of knowledge such as physics, chemistry, or engineering, in which research competences are more valued and integrated into organizations' decision-making processes. If we want to make the management scholars' skills visible and make known to the professional world the benefits of implementing the academic literature, business schools should encourage and reward sabbaticals or other periods of release time, such as teaching load reductions, to develop collaborative research projects within organizations. Similarly, current reward systems could also incentivize web-enabled communication channels and other effective dissemination tools such as social media. Forums or professional social networks could serve as a meeting point between real problems described by practitioners and relevant research opportunities for scholars.

As we have seen, the problems identified pose great challenges for the academics in the discipline that would require deep changes in the academic culture of the field. However, the change is far from being easy. The challenges that it involves require collective responses from a multitude of actors involved, who should interact constructively, cutting across jurisdictional boundaries and reaching a wider consensus. 


\section{Author contributions}

The authors appear in alphabetical order and have contributed equitably to this work.

\section{Declaration of conflicting interests}

The author(s) declared no potential conflicts of interest with respect to the research, authorship, and/or publication of this article.

\section{Funding}

The author(s) disclosed receipt of the following financial support for the research, authorship, and/or publication of this article: This study has benefited from financing from the Research Project ECO2014-56580-R of the Spanish Ministry of Economy and Competitively, and the Research Projects P12-SEJ-1810 and P12-SEJ-1618 from the Andalusia Government (Spain) and PR2016-018 (Research Projects University of Cadiz).

\section{ORCID iD}

Jesús de Frutos-Belizón (iD https://orcid.org/0000-0002-31946910

\section{Notes}

1. CRRBM was founded in 2015 , by 24 senior business professors around the world (10 countries) representing the five core business disciplines of accounting, finance, management, marketing, and operations management. More information is available at: https://www.rrbm.network/.

2. Initially, these terms were used as search criteria for title, abstract, and keywords searches. Our initial search was carried out using basic keywords in this field of knowledge, such as "research-practice gap," "publication practices," "replication," "management research/field," "rigor-relevance gap," "science-practice gap," and "ethical problems." This first selection of keywords and lexemes, related to criticisms in the field of management research, was based on reviews that had previously identified other problems. However, we decided that given the great variety and combination of words used in criticisms, it was necessary to try to define search terms that accurately represented the field analyzed. Therefore, to make searches as complete as possible and to increase the validity of the search terms, we reviewed the most relevant and influential editorials and highly positioned papers to identify missing keywords (snowball method). This step allowed us to refine our search and use other specific search terms, such as "quantitative/qualitative research" or "reward systems." Finally, the search terms included keyword combinations with Boolean operators ("and" or "or"), when we performed multiple extra searches combining basic keywords (such as "science-practice gap" AND "management field," or "research-practice gap" AND "management"). In the advanced search process, we also include different exclusion/inclusion criteria previously explained, such as the quality criteria of the scientific journals and the timeframe restrictions for our search. However, a manual filter of the results was subsequently performed to confirm that each identified article addressed the thematic scope of the literature review.

\section{References}

Agarwal, R., \& Hoetker, G. (2007). A Faustian bargain? The growth of management and its relationship with related disciplines. Academy of Management Journal, 50(6), 13041322.

Aguinis, H., Cascio, W. F., \& Ramani, R. S. (2017). Science's reproducibility and replicability crisis: International business is not immune. Journal of International Business Studies, 48, 653-663.

Aguinis, H., Gottfredson, R. K., \& Joo, H. (2013). Best-practice recommendations for defining, identifying, and handling outliers. Organizational Research Methods, 16(2), 270-301.

Aguinis, H., Hill, N. S., \& Bailey, J. R. (2021). Best practices in data collection and preparation: Recommendations for reviewers, editors, and authors. Organizational Research Methods, 24(4), 678-693. https://doi.org/10.1177/1094428119836485

Aguinis, H., Ramani, R. S., \& Alabduljader, N. (2018). What you see is what you get? Enhancing methodological transparency in management research. Academy of Management Annals, 12(1), 83-110.

Aguinis, H., Ramani, R. S., \& Cascio, W. F. (2020). Methodological practices in international business research: An after-action review of challenges and solutions. Journal of International Business Studies, 51(9), 1593-1608.

Aguinis, H., \& Solarino, A. M. (2019). Transparency and replicability in qualitative research: The case of interviews with elite informants. Strategic Management Journal, 40(8), 1291-1315.

Alberts, B. (2013). Impact Factors Distortions, Science, 340 (6134), 787.

Andraszewicz, S., Scheibehenne, B., Rieskamp, J., Grasman, R., Verhagen, J., \& Wagenmakers, E. J. (2015). An introduction to Bayesian hypothesis testing for management research. Journal of Management, 41(2), 521-543.

Antonakis, J. (2017). On doing better science: From thrill of discovery to policy implications. The Leadership Quarterly, 28(1), 5-21.

Audretsch, D. B. (2014). From the entrepreneurial university to the university for the entrepreneurial society. The Journal of Technology Transfer, 39(3), 313-321.

Banks, G. C., Pollack, J. M., Bochantin, J. E., Kirkman, B. L., Whelpley, C. E., \& O'Boyle, E. H. (2016). Management's science -practice gap: A grand challenge for all stakeholders. Academy of Management Journal, 59(6), 2205-2231.

Bansal, P., Bertels, S., Ewart, T., MacConnachie, P., \& O'Brien, J. (2012). Bridging the research-practice gap. Academy of Management Perspectives, 26(1), 73-92.

Bansal, P., \& Corley, K. (2011). The coming of age for qualitative research: Embracing the diversity of qualitative methods. Academy of Management Journal, 54(2), 233-237.

Barley, S. R. (2010). Building an institutional field to corral a government: A case to set an agenda for organization studies. Organization Studies, 31(6), 777-805.

Barley, S. R. (2016). 60th anniversary essay: Ruminations on how we became a mystery house and how we might get out. Administrative Science Quarterly, 61(1), 1-8.

Bartunek, J. M., \& Rynes, S. L. (2014). Academics and practitioners are alike and unlike: The paradoxes of academicpractitioner relationships. Journal of Management, 40(5), 1181-1201. 
Baum, J. A. (2012). The skewed few: Does "skew" signal quality among journals, articles, and academics? Journal of Management Inquiry, 21(3), 349-354.

Bedeian, A. G. (2004). Peer review and the social construction of knowledge in the management discipline. Academy of Management Learning \& Education, 3(2), 198-216.

Bedeian, A. G., Taylor, S. G., \& Miller, A. N. (2010). Management science on the credibility bubble: Cardinal sins and various misdemeanors. Academy of Management Learning \& Education, 9(4), 715-725.

Bergh, D. D., Sharp, B. M., \& Li, M. (2017). Tests for identifying "red flags" in empirical findings: Demonstration and recommendations for authors, reviewers, and editors. Academy of Management Learning \& Education, 16(1), 110-124.

Bettis, R. A. (2012). The search for asterisks: Compromised statistical tests and flawed theories. Strategic Management Journal, 33(1), 108-113.

Bettis, R. A., Ethiraj, S., Gambardella, A., Helfat, C., \& Mitchell, W. (2016). Creating repeatable cumulative knowledge in strategic management. Strategic Management Journal, $37(2), 257-261$.

Bettis, R. A., Helfat, C. E., \& Shaver, J. M. (2016). The necessity, logic, and forms of replication. Strategic Management Journal, 37(11), 2193-2203.

Birkinshaw, J., Healey, M. P., Suddaby, R., \& Weber, K. (2014). Debating the future of management research. Journal of Management Studies, 51(1), 38-55.

Bluhm, D. J., Harman, W., Lee, T. W., \& Mitchell, T. R. (2011). Qualitative research in management: A decade of progress. Journal of Management Studies, 48(8), 1866-1891.

Bosco, F. A., Aguinis, H., Field, J. G., Pierce, C. A., \& Dalton, D. R. (2016). HARKing's threat to organizational research: Evidence from primary and meta-analytic sources. Personnel Psychology, 69(3), 709-750.

Brown, M. J. (2013). Values in science beyond underdetermination and inductive risk. Philosophy of Science, 80(5), 829-839.

Bryman, A. (2016). Social research methods. Oxford University Press.

Bullinger, B., Kieser, A., \& Schiller-Merkens, S. (2015). Coping with institutional complexity: Responses of management scholars to competing logics in the field of management studies. Scandinavian Journal of Management, 31(3), 437-450.

Butler, L. (2003). Explaining Australia's increased share of ISI publications - the effects of a funding formula based on publication counts. Research Policy, 32(1), 143-155.

Cassell, C. (2016). European qualitative research: A celebration of diversity and a cautionary tale. European Management Journal, 34(5), 453-456.

Cho, E., \& Kim, S. (2015). Cronbach's coefficient alpha: Wellknown but poorly understood. Organizational Research Methods, 18(2), 207-230.

Cohen, J. (1960). A coefficient of agreement for nominal scales. Educational and Psychological Measurement, 20, 37-46.

Cohen, D. J. (2007). The very separate worlds of academic and practitioner publications in human resource management: Reasons for the divide and concrete solutions for bridging the gap. Academy of Management Journal, 50(5), 1013-1019.

Community for Responsible Research in Business and Management. (2017). A vision of responsible research in business and management: Striving for credible and useful knowledge [White paper]. Draft for Targeted Consultation. https://rrbm.network/wp-content/uploads/2017/09/White_ Paper.pdf

Corley, K. G., \& Gioia, D. A. (2011). Building theory about theory building: What constitutes a theoretical contribution? Academy of Management Review, 36(1), 12-32.

Cornelissen, J. P. (2017). Preserving theoretical divergence in management research: Why the explanatory potential of qualitative research should be harnessed rather than suppressed. Journal of Management Studies, 54(3), 368-383.

Cortina, J. M., \& Landis, R. S. (2011). The earth is not round $(\mathrm{p}=.00)$. Organizational Research Methods, 14(2), 332-349.

Crane, A., \& Matten, D. (2016). Business ethics: Managing corporate citizenship and sustainability in the age of globalization. Oxford University Press.

Davis, G. F. (2015). Editorial essay: What is organizational research for? Administrative Science Quarterly, 60(2), 179-188.

De Frutos-Belizón, J., Martín-Alcázar, F., \& Sánchez-Gardey, G. (2019). Reviewing the "Valley of Death" between management research and management practice. Management Research Review, 42(8), 926-953.

De Man, A. P., Luvison, D., \& de Leeuw, T. (In press). A temporal view on the academic-practitioner gap. Journal of Management Inquiry. Advance online publication. https:// doi.org/10.1177/1056492620982375

DORA Declaration. (2012). The San Francisco Declaration on Research Assessment. Available at: http://www.ascb.org/dora/

Douglas, H. (2009). Science, policy, and the value-free ideal. University of Pittsburgh Press.

Drucker, P. (1974). Management: Tasks, responsibilities and priorities. Heinemann.

Espeland, W. N., \& Sauder, M. (2007). Rankings and reactivity: How public measures recreate social worlds. American Journal of Sociology, 113(1), 1-40.

Ethiraj, S. K., Gambardella, A., \& Helfat, C. E. (2016). Replication in strategic management. Strategic Management Journal, 37(11), 2191-2192.

Fanelli, D. (2012). Negative results are disappearing from most disciplines and countries. Scientometrics, 90(3), 891-904.

Fleiss, J. L. (1981). Balanced incomplete block designs for inter-rater reliability studies. Applied Psychological Measurement, 5(1), 105-112.

Fochler, M., Felt, U., \& Müller, R. (2016). Unsustainable growth, hyper-competition, and worth in life science research: Narrowing evaluative repertoires in doctoral and postdoctoral scientists' work and lives. Minerva, 54(2), 175-200.

George, G. (2014). Rethinking management scholarship. Academy of Management Journal, 57(1), 1-6.

George, G., Howard-Grenville, J., Joshi, A., \& Tihanyi, L. (2016). Understanding and tackling societal grand challenges through management research. Academy of Management Journal, 59(6), 1880-1895.

Gibbert, M., Nair, L. B., Weiss, M., \& Hoegl, M. (2021). Using outliers for theory building. Organizational Research Methods, 24(1), 172-181.

Gioia, D. A., Corley, K. G., \& Hamilton, A. L. (2013). Seeking qualitative rigor in inductive research: Notes on the Gioia 
methodology. Organizational Research Methods, 16(1), $15-31$.

Goldfarb, B., \& King, A. A. (2016). Scientific apophenia in strategic management research: Significance tests \& mistaken inference. Strategic Management Journal, 37(1), 167-176.

Gordon, R. A., \& Howell, J. E. (1959). Higher education for business. The Journal of Business Education, 35(3), 115-117.

Guerrero, M., \& Urbano, D. (2012). The development of an entrepreneurial university. The Journal of Technology Transfer, 37(1), 43-74.

Hambrick, D. C. (1994). What if the academy actually mattered? Academy of Management Review, 19(1), 11-16.

Hammarfelt, B. (2017). Recognition and reward in the academy: Valuing publication oeuvres in biomedicine, economics and history. Aslib Journal of Information Management, 69(5), 607-623.

Hammarfelt, B., \& De Rijcke, S. (2015). Accountability in context: Effects of research evaluation systems on publication practices, disciplinary norms, and individual working routines in the faculty of Arts at Uppsala University. Research Evaluation, 24(1), 63-77.

Hangel, N., \& Schmidt-Pfister, D. (2017). Why do you publish? On the tensions between generating scientific knowledge and publication pressure. Aslib Journal of Information Management, 69(5), 529-544.

Harley, B. (2015). The one best way? "Scientific" research on HRM and the threat to critical scholarship. Human Resource Management Journal, 25(4), 399-407.

Hemlin, S., \& Rasmussen, S. B. (2006). The shift in academic quality control. Science, Technology, \& Human Values, 31(2), 173-198.

Hicks, D., Wouters, P., Waltman, L., De Rijcke, S., \& Rafols, I. (2015). The Leiden Manifesto for research metrics. Nature, 520(7548), 429-431.

Hodgkinson, G. P., \& Rousseau, D. M. (2009). Bridging the rigour -relevance gap in management research: It's already happening!. Journal of Management Studies, 46(3), 534-546.

Hollenbeck, J. R., \& Wright, P. M. (2017). Harking, sharking, and tharking: Making the case for post hoc analysis of scientific data. Journal of Management, 43(1), 5-18.

Honig, B., Lampel, J., Baum, J. A., Glynn, M. A., Jing, R., Lounsbury, M., Schübler, E., Sirmon, D., Tsui, A., Walsh, J., \& Van Witteloostuijn, A. (2018). Reflections on scientific misconduct in management: Unfortunate incidents or a normative crisis? Academy of Management Perspectives, 32(4), 412-442.

Honig, B., Lampel, J., Siegel, D., \& Drnevich, P. (2017). Special section on ethics in management research: Norms, identity, and community in the 21 st century. Academy of Management Learning \& Education, 16(1), 84-93.

Hubbard, R. (2016). Corrupt research: The case for reconceptualizing empirical management and social science. SAGE.

Ingwersen, P., \& Larsen, B. (2014). Influence of a performance indicator on Danish research production and citation impact 2000-12. Scientometrics, 101(2), 1325-1344.

Jebb, A. T., \& Woo, S. E. (2015). A Bayesian primer for the organizational sciences: The "two sources" and an introduction to BugsXLA. Organizational Research Methods, 18(1), 92-132.

Jonsen, K., Fendt, J., \& Point, S. (2018). Convincing qualitative research: What constitutes persuasive writing? Organizational Research Methods, 21(1), 30-67.
Kelemen, M., \& Bansal, P. (2002). The conventions of management research and their relevance to management practice. British Journal of Management, 13(2), 97-108.

Kieser, A., \& Leiner, L. (2009). Why the rigour-relevance gap in management research is unbridgeable. Journal of Management Studies, 46(3), 516-533.

Kieser, A., \& Leiner, L. (2012). Collaborate with practitioners: But beware of collaborative research. Journal of Management Inquiry, 21, 14-28.

Kieser, A., Nicolai, A., \& Seidl, D. (2015). The practical relevance of management research: Turning the debate on relevance into a rigorous scientific research program. Academy of Management Annals, 9(1), 143-233.

Kriegeskorte, N. (2012). Open evaluation: A vision for entirely transparent post-publication peer review and rating for science. Frontiers in Computational Neuroscience, 6, Article 79.

Kruschke, J. K., Aguinis, H., \& Joo, H. (2012). The time has come: Bayesian methods for data analysis in the organizational sciences. Organizational Research Methods, 15(4), 722-752.

Lebel, J., \& McLean, R. (2018). A better measure of research from the global south. Nature, 559(7712), 23-26.

Leung, K. (2011). Presenting post hoc hypotheses as a priori: Ethical and theoretical issues. Management and Organization Review, 7(3), 471-479.

Lewin, A. Y., Chiu, C. Y., Fey, C. F., Levine, S. S., McDermott, G., Murmann, J. P., \& Tsang, E. (2016). The critique of empirical social science: New policies at management and organization review. Management and Organization Review, 12(4), 649-658.

Macdonald, S., \& Kam, J. (2011). The skewed few: People and papers of quality in management studies. Organization, 18(4), 467-475.

Mathieu, J. E. (2016). The problem with [in] management theory. Journal of Organizational Behavior, 37(8), 1132-1141.

McKee, R. A., \& Miller, C. C. (2015). Institutionalizing Bayesianism within the organizational sciences: A practical guide featuring comments from eminent scholars. Journal of Management, 41(2), 471-490.

McLeod, A., Savage, A., \& Simkin, M. G. (2018). The ethics of predatory journals. Journal of Business Ethics, 153(1), 121-131.

McShane, B. B., \& Gal, D. (2015). Blinding us to the obvious? The effect of statistical training on the evaluation of evidence. Management Science, 62(6), 1707-1718.

Merton, R. K. (1957). Priorities in scientific discovery: A chapter in the sociology of science. American Sociological Review, 22(6), 635-659.

Merton, R. K. (1973). The sociology of science: Theoretical and empirical investigations. University of Chicago Press.

Mohrman, S. A., \& Lawler, E. (2011). Useful research: Advancing theory and practice. Berrett-Koehler.

Molina-Azorín, J. F., Pereira-Moliner, J., López-Gamero, M. D., Pertusa-Ortega, E. M., \& Tarí, J. J. (2020). Multilevel research: Foundations and opportunities in management. BRQ Business Research Quarterly, 23(4), 319-333.

Murphy, K. R., \& Aguinis, H. (2019). HARKing: How badly can cherry-picking and question trolling produce bias in published results? Journal of Business and Psychology, 34(1), 1-17.

Nosek, B. A., Spies, J. R., \& Motyl, M. (2012). Scientific utopia: II. Restructuring incentives and practices to promote truth 
over publishability. Perspectives on Psychological Science, 7(6), 615-631.

O'Kane, P., Smith, A., \& Lerman, M. P. (2021). Building transparency and trustworthiness in inductive research through computer-aided qualitative data analysis software. Organizational Research Methods, 24(1), 104-139.

Orlitzky, M. (2012). How can significance tests be deinstitutionalized? Organizational Research Methods, 15(2), 199-228.

Osterloh, M., \& Frey, B. S. (2020). How to avoid borrowed plumes in academia. Research Policy, 49(1), 103831.

Pettigrew, A., \& Starkey, K. (2016). From the guest editors: The legitimacy and impact of business schools-Key issues and a research agenda. Academy of Management Learning \& Education, 15(4), 649-664.

Pierson, F. C. (1959). The education of American Businessmen: A study of university college programs in business administration. McGraw-Hill.

Popper, K. R. (1959). The propensity interpretation of probability. The British Journal for the Philosophy of Science, 10(37), 25-42.

Porter, L. W., \& McKibbin, L. E. (1988). Management education and development: Drift or thrust into the 21st century? McGraw-Hill.

Potter, W. J., \& Levine-Donnerstein, D. (1999). Rethinking validity and reliability in content analysis. Journal of Applied Communication Research, 27(3), 258-284.

Pratt, M. G. (2009). From the editors: For the lack of a boilerplate: Tips on writing up (and reviewing) qualitative research. Academy of Management Journal, 52(5), 856-862.

Quan, W., Chen, B., \& Shu, F. (2017). Publish or impoverish: An investigation of the monetary reward system of science in China (1999-2016). Aslib Journal of Information Management, 69(5), 486-502.

Ramos-Rodríguez, A. R., \& Ruíz-Navarro, J. (2004). Changes in the intellectual structure of strategic management research: A bibliometric study of the Strategic Management Journal, 1980-2000. Strategic Management Journal, 25(10), 9811004.

Roloff, J., \& Zyphur, M. J. (2019). Null findings, replications and preregistered studies in business ethics research. Journal of Business Ethics, 160(3), 609-619.

Rousseau, D. M., Manning, J., \& Denyer, D. (2008). Evidence in management and organizational science: Assembling the field's full weight of scientific knowledge through syntheses, Academy of Management Annals, 2 (1), 475-515.

Runfola, A., Perna, A., Baraldi, E., \& Gregori, G. L. (2017). The use of qualitative case studies in top business and management journals: A quantitative analysis of recent patterns. European Management Journal, 35(1), 116-127.

Sam, C., \& Van Der Sijde, P. (2014). Understanding the concept of the entrepreneurial university from the perspective of higher education models. Higher Education, 68(6), 891-908.

Sartal, A., González-Loureiro, M., \& Vázquez, X. H. (2021). Meta-analyses in management: What can we learn from clinical research? BRQ Business Research Quarterly, 24(1), 91-111.

Schwab, A., Abrahamson, E., Starbuck, W. H., \& Fidler, F. (2011). Perspective-Researchers should make thoughtful assessments instead of null-hypothesis significance tests. Organization Science, 22(4), 1105-1120.
Shani, A. B., \& Coghlan, D. (2014). Collaborate with practitioners: An alternative perspective a rejoinder to Kieser and Leiner (2012). Journal of Management Inquiry, 23(4), 433-437.

Shapiro, D. L., Kirkman, B. L., \& Courtney, H. G. (2007). Perceived causes and solutions of the translation problem in management research. Academy of Management Journal, 50(2), 249-266.

Simon, H. A. (1967). The business school a problem in organizational design. Journal of Management Studies, 4(1), 1-16.

Stahl, G. K., Brewster, C. J., Collings, D. G., \& Hajro, A. (2020). Enhancing the role of human resource management in corporate sustainability and social responsibility: A multistakeholder, multidimensional approach to HRM. Human Resource Management Review, 30(3), 100708.

Starbuck, W. H. (2016). 60th anniversary essay: How journals could improve research practices in social science. Administrative Science Quarterly, 61(2), 165-183.

Starkey, K., Hatchuel, A., \& Tempest, S. (2009). Management research and the new logics of discovery and engagement. Journal of Management Studies, 46(3), 547-558.

Suddaby, R. (2014). Indigenous management theory: Why management theory is under attack (and what we can do to fix it). In J. A. Miles (Ed.), New directions in management and organization theory (pp. 457-468). Cambridge Scholars.

Symon, G., Cassell, C., \& Johnson, P. (2018). Evaluative practices in qualitative management research: A critical review. International Journal of Management Reviews, 20(1), 134 154.

Taylor, F. W. (1914). The principles of scientific management. Harper.

Thunnissen, M., \& Gallardo-Gallardo, E. (2019). Rigor and relevance in empirical TM research: Key issues and challenges. BRQ Business Research Quarterly, 22(3), 171-180.

Tranfield, D., Denyer, D., \& Smart, P. (2003). Towards a methodology for developing evidence-informed management knowledge by means of systematic review. British Journal of Management, 14(3), 207-222.

Tsang, E. W. (2016). The philosophy of management research. Taylor \& Francis.

Tsui, A. S. (2013). The spirit of science and socially responsible scholarship. Management and Organization Review, 9(3), 375-394.

Tsui, A. S. (2016). Reflections on the so-called value-free ideal: A call for responsible science in the business schools. Cross Cultural \& Strategic Management, 23(1), 4-28.

Tsui, A. S., \& Hollenbeck, J. R. (2009). Successful authors and effective reviewers: Balancing supply and demand in the organizational sciences. Organizational Research Methods, 12(2), 259-275.

Tsui, A. S., \& Jia, L. (2013). Calling for humanistic scholarship in China. Management and Organization Review, 9(1), 1-15.

Üsdiken, B. (2014). Centres and peripheries: Research styles and publication patterns in "top" US journals and their European alternatives, 1960-2010. Journal of Management Studies, 51(5), 764-789.

Van Baalen, P., \& Karsten, L. (2012). The evolution of management as an interdisciplinary field. Journal of Management History, 18(2), 219-237.

van Witteloostuijn, (2016). What happened to Popperian falsification? Publishing neutral and negative findings: Moving 
away from biased publication practices. Cross Cultural \& Strategic Management, 23 (3), 481-508.

Varela, D., Benedetto, G., \& Sanchez-Santos, J. M. (2014). Editorial statement: Lessons from Goodhart's law for the management of the journal. European Journal of Government and Economics, 3(2), 100-103.

Vogel, D., \& Homberg, F. (2021). P-hacking, P-curves, and the PSM-performance relationship: Is there evidential value? Public Administration Review, 81(2), 191-204.

Walsh, I., Holton, J. A., Bailyn, L., Fernandez, W., Levina, N., \& Glaser, B. (2015). Rejoinder: Moving the management field forward. Organizational Research Methods, 18(4), 620-628.
Walsh, J. P., Weber, K., \& Margolis, J. D. (2003). Social issues and management: Our lost cause found. Journal of Management, 29(6), 859-881.

Watermeyer, R., \& Chubb, J. (2019). Evaluating "impact" in the UK's Research Excellence Framework (REF): Liminality, looseness and new modalities of scholarly distinction. Studies in Higher Education, 44(9), 15541566.

Wright, P. M. (2017). Making great theories. Journal of Management Studies, 54(3), 384-390.

Zupic, I., \& Čater, T. (2015). Bibliometric methods in management and organization. Organizational Research Methods, 18(3), 429-472.

\section{Appendix I}

Table 5. Key contributions.

\begin{tabular}{|c|c|c|c|}
\hline Authors & Title & Journal & Core contribution \\
\hline $\begin{array}{l}\text { guinis et al. } \\
017)\end{array}$ & $\begin{array}{l}\text { Science's reproducibility and } \\
\text { replicability crisis: International } \\
\text { business is not immune }\end{array}$ & $\begin{array}{l}\text { Journal of International } \\
\text { Business Studies }\end{array}$ & $\begin{array}{l}\text { The paper addresses five common practices that } \\
\text { capitalize on chance. In addition, this paper offers } \\
\text { actionable strategies to improve the reproducibility and } \\
\text { replicability. }\end{array}$ \\
\hline $\begin{array}{l}\text { Aguinis et al. } \\
(2018)\end{array}$ & $\begin{array}{l}\text { What You See Is What You } \\
\text { Get? Enhancing Methodological } \\
\text { Transparency in Management } \\
\text { Research }\end{array}$ & $\begin{array}{l}\text { Academy of } \\
\text { Management Annals }\end{array}$ & $\begin{array}{l}\text { The paper reviews the literature on evidence-based } \\
\text { best practices on how to enhance methodological } \\
\text { transparency. }\end{array}$ \\
\hline $\begin{array}{l}\text { guinis et al. } \\
021)\end{array}$ & $\begin{array}{l}\text { Best practices in data } \\
\text { collection and preparation: } \\
\text { Recommendations for } \\
\text { reviewers, editors, and authors }\end{array}$ & $\begin{array}{l}\text { Organizational } \\
\text { Research Methods }\end{array}$ & $\begin{array}{l}\text { The paper offers best-practice recommendations for } \\
\text { journal reviewers, editors, and authors regarding data } \\
\text { collection and preparation. }\end{array}$ \\
\hline $\begin{array}{l}\text { guinis et al. } \\
\text { 020) }\end{array}$ & $\begin{array}{l}\text { Methodological practices in } \\
\text { international business research: } \\
\text { An after-action review of } \\
\text { challenges and solutions }\end{array}$ & $\begin{array}{l}\text { Journal of International } \\
\text { Business Studies }\end{array}$ & $\begin{array}{l}\text { The paper describes the four most widespread } \\
\text { contemporary methodological challenges, offering } \\
\text { solutions to address these challenges. }\end{array}$ \\
\hline $\begin{array}{l}\text { ndraszewicz } \\
\text { al. }(2015)\end{array}$ & $\begin{array}{l}\text { An introduction to Bayesian } \\
\text { hypothesis testing for } \\
\text { management research }\end{array}$ & Journ & $\begin{array}{l}\text { The paper describes the conceptual and practical } \\
\text { advantages of an alternative analysis method: Bayesian } \\
\text { hypothesis testing and model selection using the Bayes } \\
\text { factor. }\end{array}$ \\
\hline $\begin{array}{l}\text { ntonakis } \\
2017)\end{array}$ & $\begin{array}{l}\text { On doing better science: From } \\
\text { thrill of discovery to policy } \\
\text { implications }\end{array}$ & $\begin{array}{l}\text { The Leadership } \\
\text { Quarterly }\end{array}$ & $\begin{array}{l}\text { The paper discusses five serious "diseases" in the } \\
\text { Management field that stifle useful research output. }\end{array}$ \\
\hline $\begin{array}{l}\text { Aguinis and } \\
\text { Solarino (2019) }\end{array}$ & $\begin{array}{l}\text { Transparency and replicability in } \\
\text { qualitative research: The case of } \\
\text { interviews with elite informants }\end{array}$ & $\begin{array}{l}\text { Strategic Management } \\
\text { Journal }\end{array}$ & $\begin{array}{l}\text { The paper uses interviews with elite informants as } \\
\text { a case study to illustrate the need to expand the } \\
\text { discussion of transparency and replicability to qualitative } \\
\text { methodology. }\end{array}$ \\
\hline $\begin{array}{l}\text { Bansal and } \\
\text { Corley }(20 \mathrm{II})\end{array}$ & $\begin{array}{l}\text { The coming of age for qualitative } \\
\text { research: Embracing the diversity } \\
\text { of qualitative methods }\end{array}$ & $\begin{array}{l}\text { Academy of } \\
\text { Management Journal }\end{array}$ & $\begin{array}{l}\text { Through a dialogue of editors, the paper identifies some } \\
\text { gaps in qualitative research in the management field and } \\
\text { ponders on opportunities for further development. }\end{array}$ \\
\hline $\begin{array}{l}\text { Bansal et al. } \\
(20 \mid 2)\end{array}$ & $\begin{array}{l}\text { Bridging the research-practice } \\
\text { gap }\end{array}$ & $\begin{array}{l}\text { Academy of } \\
\text { Management } \\
\text { Perspectives }\end{array}$ & $\begin{array}{l}\text { The paper describes experiences that showed that the } \\
\text { paradoxes that underlie the relationship between research } \\
\text { and practice make it difficult to overcome this gap. }\end{array}$ \\
\hline
\end{tabular}


Table 5. (Continued)

\begin{tabular}{|c|c|c|c|}
\hline Authors & Title & Journal & Core contribution \\
\hline Barley (2016) & $\begin{array}{l}\text { 60th anniversary essay: } \\
\text { Ruminations on how we became } \\
\text { a mystery house and how we } \\
\text { might get out }\end{array}$ & $\begin{array}{l}\text { Administrative Science } \\
\text { Quarterly }\end{array}$ & $\begin{array}{l}\text { This essay analyzes different concerns about } \\
\text { management field research and describes the reasons } \\
\text { why novelty has become such a valued commodity in } \\
\text { organizational theory. }\end{array}$ \\
\hline $\begin{array}{l}\text { Bartunek and } \\
\text { Rynes }(2014)\end{array}$ & $\begin{array}{l}\text { Academics and practitioners are } \\
\text { alike and unlike: The paradoxes } \\
\text { of academic-practitioner } \\
\text { relationships }\end{array}$ & Journal of Management & $\begin{array}{l}\text { This essay identifies and suggests ways of working within } \\
\text { the academic and professional community to encourage } \\
\text { research and the construction of collaborative theories. }\end{array}$ \\
\hline Baum (20I2) & $\begin{array}{l}\text { The skewed few: Does "skew" } \\
\text { signal quality among journals, } \\
\text { articles, and academics? }\end{array}$ & $\begin{array}{l}\text { Journal of Management } \\
\text { Inquiry }\end{array}$ & $\begin{array}{l}\text { The paper discusses bias in assigning high-quality to top- } \\
\text { notch journals without considering individual impact. }\end{array}$ \\
\hline $\begin{array}{l}\text { Bedeian et al. } \\
(2010)\end{array}$ & $\begin{array}{l}\text { Management science on the } \\
\text { credibility bubble: Cardinal sins } \\
\text { and various misdemeanors }\end{array}$ & $\begin{array}{l}\text { Academy of } \\
\text { Management Learning } \\
\text { \& Education }\end{array}$ & $\begin{array}{l}\text { This essay presents the results of a survey that collected } \\
\text { I I different types of questionable research behaviors. }\end{array}$ \\
\hline $\begin{array}{l}\text { Bergh et al. } \\
(2017)\end{array}$ & $\begin{array}{l}\text { Tests for identifying "Red } \\
\text { Flags" in empirical findings: } \\
\text { Demonstration and }\end{array}$ & $\begin{array}{l}\text { Academy of } \\
\text { Management Learning } \\
\text { \& Education }\end{array}$ & $\begin{array}{l}\text { This paper describes three tests that can be applied } \\
\text { to most empirical articles to assess the accuracy of } \\
\text { reported findings. }\end{array}$ \\
\hline
\end{tabular}

Bettis (2012) The search for asterisks: Compromised statistical tests and flawed theories

Bettis, Ethiraj, Creating repeatable cumulative et al. (2016) knowledge in strategic management.

Bettis, Helfat, The necessity, logic, and forms and Shaver

Bluhm et al. of replication

Qualitative research in management: A decade of progress

Bosco et al. (2016)

HARKing's threat to organizational research: Evidence from primary and meta-analytic sources

Bullinger et al. Coping with institutional (2015) complexity: Responses of management scholars to competing logics in the field of management studies

Cassell (2016) European qualitative research: A celebration of diversity and a cautionary tale

Cho and Kim Cronbach's coefficient alpha:

Cornelissen (2017) Well known but poorly understood

Strategic Management Journal

Strategic Management Journal

Strategic Management Journal

This paper criticizes the incorrect use of tests of statistical significance. In addition, they describe some tips and guidelines to address these limitations.

This editorial tries to generate debate among the academic community in management field on the replicability and reliability of the knowledge generated.

This introductory editorial analyzes different replication studies and proposes different recommendations to improve and encourage their development.

Journal of Management This paper reviews the qualitative literature published Studies in the management field to evaluate its legitimacy, advances in qualitative techniques and its contribution to the generation of knowledge.

Personnel Psychology This paper evaluates the negative consequences of formulating the hypotheses of a study after the results of the study are known.

Scandinavian Journal of This paper analyzes the responses of management Management scholars to the research practice-gap. Specifically, the authors argue that the separation between the two communities is related to different research logics oriented toward basic research or relevant knowledge.

European Management This paper reviews the qualitative European literature, Journal analyzing and highlighting its development and diversity of techniques.

Organizational This paper tries to clarify six common misconceptions Research Methods about the Cronbach's alpha coefficient that lead to its misinterpretation.

Journal of Management This position paper shows concern about the tendency Studies to develop qualitative methodology based on analytical methods.

the explanatory potential of qualitative research should be harnessed rather than suppressed

Corley and

Gioia (20II)

Building theory about theory building: what constitutes a theoretical contribution?

Cortina and Landis (201 I)

The earth is not round

\section{Academy of Management Review}

Organizational Research Methods
This paper develops a critique of the originality and usefulness of the theoretical contributions developed in management field.

This paper criticizes the dependence and inappropriate use of significance tests in management field research. 
Table 5. (Continued)

\begin{tabular}{|c|c|c|c|}
\hline Authors & Title & Journal & Core contribution \\
\hline Davis (2015) & $\begin{array}{l}\text { Editorial essay: What is } \\
\text { organizational research for? }\end{array}$ & $\begin{array}{l}\text { Administrative Science } \\
\text { Quarterly }\end{array}$ & $\begin{array}{l}\text { This essay proposes a discussion on the research } \\
\text { standards proposed by the journals and the academic } \\
\text { rewards that guide research in management field. }\end{array}$ \\
\hline $\begin{array}{l}\text { De Frutos- } \\
\text { Belizón et al. } \\
(2019)\end{array}$ & $\begin{array}{l}\text { Reviewing the "Valley of } \\
\text { Death" between management } \\
\text { research and management } \\
\text { practice: Toward a reorienting } \\
\text { of paradigm assumptions in } \\
\text { management science }\end{array}$ & $\begin{array}{l}\text { Management Research } \\
\text { Review }\end{array}$ & $\begin{array}{l}\text { This paper reviews the literature on the research- } \\
\text { practice gap in management field. In addition, it } \\
\text { proposes a reorientation of the assumption paradigm in } \\
\text { management science. }\end{array}$ \\
\hline $\begin{array}{l}\text { De Man et al. } \\
(2020)\end{array}$ & $\begin{array}{l}\text { A temporal view on the } \\
\text { academic- practitioner gap }\end{array}$ & $\begin{array}{l}\text { Journal of Management } \\
\text { Inquiry }\end{array}$ & $\begin{array}{l}\text { This paper develops a review of the literature on the } \\
\text { research-practice gap. The review shows that opinions } \\
\text { diverge over time and that the gap is not static and } \\
\text { increases and decreases cyclically. }\end{array}$ \\
\hline George (2014) & $\begin{array}{l}\text { Rethinking management } \\
\text { scholarship }\end{array}$ & $\begin{array}{l}\text { Academy of } \\
\text { Management Journal }\end{array}$ & $\begin{array}{l}\text { This editorial reflects on some concerns in management } \\
\text { field research, such as the peer review and plagiarism } \\
\text { process for manuscript submissions, and the importance } \\
\text { of preserving the author's voice in manuscript peer } \\
\text { review processes. }\end{array}$ \\
\hline $\begin{array}{l}\text { Gibbert et al. } \\
(202 I)\end{array}$ & Using outliers for theory building & $\begin{array}{l}\text { Organizational } \\
\text { Research Methods }\end{array}$ & $\begin{array}{l}\text { This paper discusses methodological limitations in } \\
\text { papers that build theories and provides a roadmap for } \\
\text { empirical researchers. }\end{array}$ \\
\hline $\begin{array}{l}\text { Gioia et al. } \\
(2013)\end{array}$ & $\begin{array}{l}\text { Seeking qualitative rigor in } \\
\text { inductive research: Notes on the } \\
\text { Gioia methodology }\end{array}$ & $\begin{array}{l}\text { Organizational } \\
\text { Research Methods }\end{array}$ & $\begin{array}{l}\text { In this paper the authors highlight the richness and } \\
\text { potential of qualitative research in the management } \\
\text { field. In addition, a systemic approach is proposed to } \\
\text { provide "qualitative rigor" based on the articulation of } \\
\text { grounded theory. }\end{array}$ \\
\hline $\begin{array}{l}\text { Hangel and } \\
\text { Schmidt-Pfister } \\
(2017)\end{array}$ & $\begin{array}{l}\text { Why do you publish? On the } \\
\text { tensions between generating } \\
\text { scientific knowledge and } \\
\text { publication pressure }\end{array}$ & $\begin{array}{l}\text { Aslib Journal } \\
\text { of Information } \\
\text { Management }\end{array}$ & $\begin{array}{l}\text { This paper develops a qualitative study to analyze } \\
\text { the motivations of researchers to publish throughout } \\
\text { different stages in the academic career. The findings } \\
\text { confirm the pronounced emphasis on publishing even at } \\
\text { all stages of the academic career. }\end{array}$ \\
\hline Harley (20I5) & $\begin{array}{l}\text { The one best way? "Scientific" } \\
\text { research on HRM and the threat } \\
\text { to critical scholarship }\end{array}$ & $\begin{array}{l}\text { Human Resource } \\
\text { Management Journal }\end{array}$ & $\begin{array}{l}\text { This paper criticizes the emphasis on the positivist } \\
\text { approach in management field research. The authors } \\
\text { call for greater methodological pluralism and the } \\
\text { development of alternatives that guide the research } \\
\text { paradigm. }\end{array}$ \\
\hline $\begin{array}{l}\text { Hollenbeck and } \\
\text { Wright (2017) }\end{array}$ & $\begin{array}{l}\text { Harking, sharking, and tharking: } \\
\text { Making the case for post hoc } \\
\text { analysis of scientific data }\end{array}$ & Journal of Management & $\begin{array}{l}\text { This editorial discusses the problems generated by some } \\
\text { bad practices in management research. In response to } \\
\text { these concerns, authors explain how authors, reviewers, } \\
\text { and editors can best take advantage of post hoc } \\
\text { analyses. }\end{array}$ \\
\hline $\begin{array}{l}\text { Honig et al. } \\
(2018)\end{array}$ & $\begin{array}{l}\text { Reflections on scientific } \\
\text { misconduct in management: } \\
\text { Unfortunate incidents or a } \\
\text { normative crisis? }\end{array}$ & $\begin{array}{l}\text { Academy of } \\
\text { Management } \\
\text { Perspectives }\end{array}$ & $\begin{array}{l}\text { This editorial shows the opinion of nine management } \\
\text { scholars with different backgrounds and careers on the } \\
\text { main problems of management research. }\end{array}$ \\
\hline $\begin{array}{l}\text { Honig et al. } \\
(2017)\end{array}$ & $\begin{array}{l}\text { Special section on ethics in } \\
\text { management research: Norms, } \\
\text { identity, and community in the } \\
2 \text { lst century }\end{array}$ & $\begin{array}{l}\text { Academy of } \\
\text { Management Learning } \\
\text { \& Education }\end{array}$ & $\begin{array}{l}\text { This editorial proposes a discussion on the growing } \\
\text { competition to publish and the effects on certain } \\
\text { ethical decisions in the development of research in the } \\
\text { management field. }\end{array}$ \\
\hline $\begin{array}{l}\text { Jebb and Woo } \\
(2015)\end{array}$ & $\begin{array}{l}\text { A Bayesian primer for the } \\
\text { organizational sciences: } \\
\text { The "Two Sources" and an } \\
\text { introduction to BugsXLA }\end{array}$ & $\begin{array}{l}\text { Organizational } \\
\text { Research Methods }\end{array}$ & $\begin{array}{l}\text { This article aims to minimize the challenges that } \\
\text { Bayesian methods pose for researchers in management } \\
\text { field. }\end{array}$ \\
\hline $\begin{array}{l}\text { Jonsen et al. } \\
(2018)\end{array}$ & $\begin{array}{l}\text { Convincing qualitative research: } \\
\text { What constitutes persuasive } \\
\text { writing? }\end{array}$ & $\begin{array}{l}\text { Organizational } \\
\text { Research Methods }\end{array}$ & $\begin{array}{l}\text { This paper reflects on and offers recommendations } \\
\text { to improve the writing of qualitative research and } \\
\text { accelerate its dissemination. }\end{array}$ \\
\hline
\end{tabular}


Table 5. (Continued)

\begin{tabular}{ll}
\hline Authors & Title \\
\hline $\begin{array}{l}\text { Kieser and } \\
\text { Leiner (2009) }\end{array}$ & $\begin{array}{l}\text { Why the rigor-relevance gap } \\
\text { in management research is } \\
\text { unbridgeable }\end{array}$ \\
Kieser and & $\begin{array}{l}\text { Collaborate with practitioners: } \\
\text { Leiner (2012) }\end{array}$ \\
$\begin{array}{l}\text { But beware of collaborative } \\
\text { research }\end{array}$
\end{tabular}

Journal

Journal of Management This article analyzes the research-practice gap in

Studies management field through systems theory, and discusses how to bridge it.

Journal of Management This article develops a critique of those works that Inquiry consider that collaborative research between the professional world and the academic world is easy and does not entail communication problems. According to the authors, turning practitioners into co-researchers and ensuring that rigor is complemented by relevance are overrated in academic discourse.

Kieser et al. The practical relevance of management research: Turning the debate on relevance into a rigorous scientific research

Kruschke et al. The time has come: Bayesian (20I2) methods for data analysis in the organizational sciences

Leung (20II) Presenting post hoc hypotheses as a priori: Ethical and theoretical issues

Academy of Management Annals

Organizational Research Methods This article reviews the literature on the researchpractice gap in management field, providing a systematic overview of the different streams of this literature, and analyzing their strengths and weaknesses.

This article introduces Bayesian methods to management researchers and describes why and how they should be used. These methods are proposed by the authors as the solution to some methodological limitations in management research.

Management and Organization Review

This article criticizes unethical practices such as the presentation of post hoc hypotheses as if they had been developed a priori. To address these problems, the authors propose practices such as replication or descriptive research.

Lewin et al. The critique of empirical (2016) social science: new policies at management and organization review

Macdonald and The skewed few: people and Kam (20II) papers of quality in management studies

Mathieu (2016) The problem with [in] management theory

McKee and Institutionalizing Bayesianism Miller (20I5) within the organizational sciences: A practical guide featuring comments from eminent scholars

McLeod et al. The ethics of predatory journals (20I8)

McShane and Gal (2015)

Blinding us to the obvious? The effect of statistical training on the evaluation of evidence.

Molina-Azorín Multilevel research: Foundations et al. (2020) and opportunities in management

Murphy and Aguinis (2019)
Management and Organization Review management field. Management research is criticized for seeking novelty about the truth, the lack of connection with practice, and the vulnerability of its scientific claims.

Organization This paper criticizes the false quality of the research attributed only to the top scientific journals. The article critically reflects on the impact factors, highlighting that this indicator has been developed for commercial rather than academic reasons.

Journal of The article focuses on criticizing the special concern for Organizational the entertainment value of theories over their scientific Behaviour rigor or their practical value.

Journal of Management The article proposes the application of Bayesian methods as a solution to some of the methodological problems present in the field of management.

Journal of Business Ethics

Management Science

The article warns of the appearance in the field of management of predatory journals and the consequences on the integrity and rigor of the knowledge generated.

This paper criticizes the incorrect use of the significance tests in management science. The emphasis on null hypothesis significance testing may lead to interpreting

$B R Q$ Business Research This paper highlights the importance and potential of Quarterly multilevel analysis for the applicability of knowledge generated in the management field.

Journal of Business and This paper warns of the problems generated by Psychology practices such as HARKing, since they could plausibly skew the results of the study.
This editorial critically reflects on research in the the evidence dichotomously rather than continuously.
HARKing: How badly can cherry-picking and question trolling produce bias in published results? 
Table 5. (Continued)

Core contribution

\begin{tabular}{|c|c|c|}
\hline Authors & Title & Journal \\
\hline $\begin{array}{l}\text { O'Kane et al. } \\
(2021)\end{array}$ & $\begin{array}{l}\text { Building transparency and } \\
\text { trustworthiness in inductive } \\
\text { research through computer- } \\
\text { aided qualitative data analysis } \\
\text { software }\end{array}$ & $\begin{array}{l}\text { Organizational } \\
\text { Research Methods }\end{array}$ \\
\hline Orlitzky (20I2) & $\begin{array}{l}\text { How can significance tests be } \\
\text { deinstitutionalized? }\end{array}$ & $\begin{array}{l}\text { Organizational } \\
\text { Research Methods }\end{array}$ \\
\hline $\begin{array}{l}\text { Pettigrew and } \\
\text { Starkey }(2016)\end{array}$ & $\begin{array}{l}\text { From the Guest Editors: The } \\
\text { legitimacy and impact of business } \\
\text { schools-key issues and a } \\
\text { research agenda }\end{array}$ & $\begin{array}{l}\text { Academy of } \\
\text { Management Learning } \\
\text { \& Education }\end{array}$ \\
\hline Pratt (2009) & $\begin{array}{l}\text { From the Editors: For the lack } \\
\text { of a boilerplate: Tips on writing } \\
\text { up (and reviewing) qualitative } \\
\text { research }\end{array}$ & $\begin{array}{l}\text { Academy of } \\
\text { Management Journal }\end{array}$ \\
\hline $\begin{array}{l}\text { Roloff and } \\
\text { Zyphur (2019) }\end{array}$ & $\begin{array}{l}\text { Null findings, replications and } \\
\text { preregistered studies in business } \\
\text { ethics research }\end{array}$ & $\begin{array}{l}\text { Journal of Business } \\
\text { Ethics }\end{array}$ \\
\hline
\end{tabular}

This paper proposes solutions and tools to improve the credibility and transparency of the qualitative methodology in management field.

The main purpose of this article is to propose possible solutions to the methodological problem of the nullhypothesis significance tests, highly established among quantitative techniques in management science.

This editorial analyzes two core problems in management science. On one hand, the legitimacy of the scientific knowledge generated in this field of knowledge. On the other, the social impact of the research.

This editorial highlights the importance of qualitative methodology in a social science such as the field of management. In addition, methods that can encourage its definitive use in management research are discussed. In this essay, the editors analyze the bad practices present in management science. Specifically, they focus on introducing more reliable procedures that promote ethical ideas in the development of quantitative methodology.

Runfola et al. The use of qualitative case studies European Management This work focuses on analyzing the scope and (2017) in top business and management Journal journals: A quantitative analysis of recent patterns

Schwab et al. Perspective-researchers should Organization Science (20II) make thoughtful assessments instead of null-hypothesis significance tests

Shani and Coghlan (2014) Collaborate with practitioners: an alternative perspective a rejoinder to Kieser and Leiner (20I2)

Starbuck (2016) 60th anniversary essay: How journals could improve research practices in social science.

Administrative Science This essay identifies problematic properties of the quarterly

Journal of Management Inquiry characteristics of the qualitative works published in the main journals in the management field.

This paper summarizes the key criticisms that nullhypothesis significance tests have suffered over the past 20 years. In addition, it recommends alternative ways to evaluate research findings beyond significance tests.

This paper refutes those critical works with collaborative research between academics and professionals. From the authors' point of view, collaborative research tends to bridge the gap between rigor and relevance. methodological techniques used in management science. In addition, the authors propose practices to improve editorial evaluations to make research more reliable.

Starkey et al. Management research and the (2009) new logics of discovery and engagement

Journal of Management In this article, the authors defend a research paradigm in Studies management science close to design science. They argue that relevance must be a necessary condition for rigor.

Symon et al. Evaluative practices in qualitative International Journal of This article develops a critical review on the evaluation (2018) management research: A critical Management Reviews review of qualitative methodology in management field. According to the authors, positivist assumptions are producing inappropriate evaluation criteria.

Thunnissen Rigor and relevance in empirical and Gallardo- TM research: Key issues and Gallardo (2019) challenges

BRQ Business Research Quarterly This article develops a critical reflection on the quality of research in Talent Management. The authors draw on a content analysis of 174 articles to identify 9 critical questions regarding the quality of empirical research in this field.

Cross Cultural \& The fundamental purpose of this essay is to discuss the Strategic Management role of responsible science and values in management science research. responsible science in the business schools. 
Table 5. (Continued)

\begin{tabular}{|c|c|c|c|}
\hline Authors & Title & Journal & Core contribution \\
\hline Tsui (20|3) & $\begin{array}{l}\text { The spirit of science and socially } \\
\text { responsible scholarship }\end{array}$ & $\begin{array}{l}\text { Management and } \\
\text { Organization Review }\end{array}$ & $\begin{array}{l}\text { This editorial discusses the importance of the spirit } \\
\text { of responsible science in management science. The } \\
\text { arguments defended in the paper propose to orient the } \\
\text { investigation toward what should be contribution to } \\
\text { both scholarship and practice. }\end{array}$ \\
\hline $\begin{array}{l}\text { Tsui and Jia } \\
(2013)\end{array}$ & $\begin{array}{l}\text { Calling for humanistic } \\
\text { scholarship in China }\end{array}$ & $\begin{array}{l}\text { Management and } \\
\text { Organization Review }\end{array}$ & $\begin{array}{l}\text { This editorial discusses the importance of the social } \\
\text { relevance of the research developed in management. } \\
\text { Specifically, their findings show a dramatic dominance } \\
\text { of the economic approach in relation to the social } \\
\text { relevance of the research. }\end{array}$ \\
\hline Üsdiken (20|4) & $\begin{array}{l}\text { Centers and peripheries: } \\
\text { Research styles and publication } \\
\text { patterns in "Top" US journals } \\
\text { and their European alternatives }\end{array}$ & $\begin{array}{l}\text { Journal of Management } \\
\text { Studies }\end{array}$ & $\begin{array}{l}\text { This paper develops a review that attests to the } \\
\text { changes in styles of research and publication patterns in } \\
\text { management. Specifically, this study identifies a growth } \\
\text { in the development of qualitative methodology in } \\
\text { management research. The study also did not confirm } \\
\text { an increasing convergence toward US-style research. }\end{array}$ \\
\hline $\begin{array}{l}\text { Vogel and } \\
\text { Homberg } \\
(2021)\end{array}$ & $\begin{array}{l}\text { P-Hacking, P-curves, and the } \\
\text { PSM-performance }\end{array}$ & $\begin{array}{l}\text { Public Administration } \\
\text { Review }\end{array}$ & $\begin{array}{l}\text { This paper analyses how the } p \text {-hacking and selective } \\
\text { publication of significant results can have negative } \\
\text { repercussions on the scientific knowledge generated in } \\
\text { management science. The authors propose techniques } \\
\text { to evaluate the probative value of a published body of } \\
\text { research. }\end{array}$ \\
\hline $\begin{array}{l}\text { I. Walsh et al. } \\
(20 \mid 5)\end{array}$ & $\begin{array}{l}\text { Rejoinder: Moving the } \\
\text { management field forward }\end{array}$ & $\begin{array}{l}\text { Organizational } \\
\text { Research Methods }\end{array}$ & $\begin{array}{l}\text { This paper questions and rejects the unrealistic } \\
\text { paradigmatic dichotomy, positivism/quantitative/ } \\
\text { deduction versus interpretivism/qualitative/induction in } \\
\text { management science. }\end{array}$ \\
\hline
\end{tabular}

